\title{
Neck circumference and its association with cardiometabolic risk factors: a systematic review and meta-analysis
}

\author{
Asal Ataie-Jafari ${ }^{1}$, Nazli Namazi ${ }^{2}$, Shirin Djalalinia ${ }^{3,4}$, Pouria Chaghamirzayi ${ }^{5}$, Mohammad Esmaeili Abdar $^{6}$, \\ Sara Sarrafi Zadehe ${ }^{1}$, Hamid Asayesh ${ }^{7}$, Maryam Zarei ${ }^{8}$, Armita Mahdavi Gorabi ${ }^{9}$, Morteza Mansourian ${ }^{10}$ \\ and Mostafa Qorbani $i^{6,11^{*}}$
}

\begin{abstract}
Background: Recently, neck circumference (NC) has been used to predict the risk of cardiometabolic factors. This study aimed to perform a systematic review and meta-analysis to examine: (i) the sensitivity (SE) and specificity (SP) of NC to predict cardiometabolic risk factors and (ii) the association between NC and the risk of cardiometabolic parameters.

Methods: A systematic search was conducted through PubMed/Medline, Institute of Scientific Information, and Scopus, until 2017 based on the search terms of metabolic syndrome (MetS) and cardio metabolic risk factors. Randomeffect model was used to perform a meta-analysis and estimate the pooled SE, SP and correlation coefficient (CC).

Results: A total of 41 full texts were selected for systematic review. The pooled SE of greater NC to predict MetS was $65 \%(95 \% \mathrm{Cl} 58,72)$ and $77 \%(95 \% \mathrm{Cl} 55,99)$ in adult and children, respectively. Additionally, the pooled SP was 66\% $(95 \% \mathrm{Cl} 60,72)$ and $66 \%(95 \% \mathrm{Cl} 48,84)$ in adult and children, respectively. According to the results of meta-analysis in adults, NC had a positive and significant correlation with fasting blood sugar (FBS) (CC: 0.16, 95\% Cl 0.13, 0.20), HOMAIR $(0.38,95 \% \mathrm{Cl} 0.25,0.50)$, total cholesterol (TC) $(0.0795 \% \mathrm{Cl} 0.02,0.12)$, triglyceride (TG) concentrations $(0.23,95 \% \mathrm{Cl}$ $0.19,0.28)$ and low density lipoprotein cholesterol (LDL-C) $(0.14,95 \% \mathrm{Cl} 0.07,0.22)$. Among children, NC was positively associated with FBS (CC: $0.12,95 \% \mathrm{Cl} 0.07,0.16)$, TG (CC: $0.21,95 \% \mathrm{Cl} 0.17,0.25)$, and TC concentrations (CC: $0.07,95 \%$ $\mathrm{Cl} 0.02,0.12)$. However, it was not significant for LDL-C.
\end{abstract}

Conclusion: NC has a good predictive value to identify some cardiometabolic risk factors. There was a positive association between high NC and most cardiometabolic risk factors. However due to high heterogeneity, findings should be declared with caution.

Keywords: Neck circumference, Metabolic syndrome, Cardiometabolic risk factors

\footnotetext{
*Correspondence: mqorbani1379@yahoo.com

${ }^{6}$ Non-communicable Diseases Research Center, Alborz University

of Medical Sciences, Karaj, Iran

Full list of author information is available at the end of the article
}

(c) The Author(s) 2018. This article is distributed under the terms of the Creative Commons Attribution 4.0 International License (http://creativecommons.org/licenses/by/4.0/), which permits unrestricted use, distribution, and reproduction in any medium, provided you give appropriate credit to the original author(s) and the source, provide a link to the Creative Commons license, and indicate if changes were made. The Creative Commons Public Domain Dedication waiver (http://creativecommons.org/ publicdomain/zero/1.0/) applies to the data made available in this article, unless otherwise stated. 


\section{Background}

Cardiovascular diseases are dominant cause of death across the world [1]. Obesity is an important risk factor for these threats and other cardiometabolic diseases such as diabetes [2].

The association between body mass index (BMI), waist circumference (WC), and waist-to-hip ratio (WHR), indices of general or central obesity, with increased cardiometabolic risk has been proved in numerous studies [2, $3]$. However, these measures need calibrated tools such as scale, or vary throughout a day. In contrast, neck circumference (NC) is easy to measure, constant, and time-saving measure to identify overweight and obese individuals $[4,5]$. It has also been shown as a tool associated with central obesity [6], hypertension and other components of metabolic syndrome (MetS) [7]. A recent meta-analysis from six studies in children and adolescents showed that NC was moderately associated with BMI [8]. To our knowledge, there has been no meta-analysis on sensitivity (SE) and specificity (SP) of NC to identify cardiometabolic risk factors, so far. Moreover, the association between $\mathrm{NC}$ and cardiometabolic risk factors has not been examined in child population. Accordingly, we performed a systematic review on studies which assessed $\mathrm{NC}$ in association with cardiometabolic risk factors, and studies which reported SE and SP of NC to identify cardiometabolic risk factors.

\section{Methods}

This study was designed as a systematic review on the association of NC and cardio metabolic risk factors. The main related international electronic data sources of PubMed and the NLM Gateway (for MEDLINE), Institute of Scientific Information (ISI), and Scopus searched systematically. For each, strategies were run separately regarding the detailed practical instruction including filters and refining processes. The medical subject headings, Entry Terms and Emtree options were used to reach the most sensitive search.

The strategy developed based on the search terms of MetS, cardio metabolic risk that included all of related components such as glycemic indices including diabetes mellitus, blood glucose, hemoglobin A1c (HbA1c), homeostatic model assessment (HOMA), insulin resistance (IR), lipid profiles including triglycerides (TG), low density lipoprotein (LDL), high density lipoprotein cholesterol (HDL-C), total cholesterol (TC), anthropometric measures including body mass index (BMI), waist circumference (WC), NC, overweight, generalized and abdominal obesity, and blood pressure (BP) including systolic blood pressure (SBP), diastolic blood pressure (DBP), mean arterial pressure (MAP), and their sub-components. At next stage these queries added to results for
NC. Data refined for human subject without restriction on language.

We excluded papers of non-population-based studies or those with duplicate citation. For multiple publications of the same population, only the article with largest sample size was included.

The bibliographic information of searched studies saved using Endnote software and four independent reviewers completed all three steps of data refinement, including titles, abstracts and full texts review. Possible disagreements were resolved by third reviewer (M.Qh).

Using Cohen's kappa statistic, agreement between the results of data extraction of two experts (Sh.D, P.Ch) was 0.94. Data were collected through standard forms which contained author' name, publication year, location, and type of study, sample size, age range, sex, measurements details, and interested outcomes.

\section{Risk of bias assessment}

Risk of bias for studies which reported diagnostic accuracy of NC for predicting cardiometabolic risk factors was assessed using "quality assessment of diagnostic accuracy studies 2" (QUADAS2) checklist. This checklist includes four main methodological domains of study (sample selection, index test, gold standard, process and timing). According to this checklist studies were categorized as "low risk of bias", "high risk of bias" and "unclear". The quality assessment of observational studies which assessed association between NC and cardiometabolic risk factors was assessed using the Newcastle-Ottawa checklist which is adapted for types of study (cross sectional, case-control, cohort). In this checklist, each study can attain 9 scores for its quality. Four scores for the selection of study groups, two scores for the comparability of the groups, and three scores for the assessment of outcomes. A study with a Newcastle-Ottawa scale score of $\geq 6$ was considered as high quality study. Three authors (H.A, M.Z, A.M) independently evaluated the included studies. A third author (M.M) resolved any disagreements between them.

\section{Ethical considerations}

The protocol of study was approved by the ethical committee of Alborz University of Medical Science. All reviewed studies were properly cited. For more information about a certain study, we contacted the corresponding authors.

\section{Statistical analysis}

The results of diagnostic accuracy of NC to identify MetS was presented as SE, SP and the area under the curve (AUC). The overall (pooled) SE and of SP of $\mathrm{NC}$ to identify MetS according to sex and age groups 
(pediatric and adult) was estimated using random effect meta-analysis method (using the Der-Simonian and Laird method). Forest plot also was used to present result of meta-analysis schematically.

To examine the overall correlation between NC and cardiometabolic risk factors, when $r$ Pearson was reported a mean transformed correlation using r-to-z transformation procedure was used to obtain Fisher's $Z$. The standard error was also calculated based on the variance of Fisher's Z. Spearman was also converted Pearson correlation coefficients, using the following formula:

$$
\mathrm{r}_{\text {(Pearson) }}=2 * \sin \left(\mathrm{r}_{(\text {Spearman })} * \pi / 6\right)
$$

We used Der Simonian and Laird method to pool the correlation coefficients (CC). Between-study heterogeneity was assessed using the $\mathrm{I}^{2}$ statistic and $\mathrm{I}^{2}$ more than $50 \%$ considered as high heterogeneity. Findings were reported separately for adults and children. When the heterogeneity was high, we stratified the studies according to mean age (more or less than 48 years), sex (men, women, both) and continent (Asian, non-Asian) in adult populations. As the range of age in children was similar among the included studies, only sex and continent was considered for subgroup analysis. Stratification was performed when at least two studies were in each sub group. To assess publication bias when there were more than 10 effect sizes, funnel plots and Begg test was used. However, publication bias for variables with less than 10 effect sizes was examined using Egger test. P-value $<0.05$ value was considered statistically significant. All statistical analyses were performed with Stata version 12.0 (STATA Corp, College Station, TX, USA).

\section{Results}

Figure 1 shows the selection process of articles. In total, 657 records were obtained using searching through PubMed and the NLM Gateway (for MEDLINE), ISI, and Scopus. Subsequently, 325 duplicates were removed. Articles were screened by title and abstract. In addition, 4 articles were identified through reference checking. A total of 80 full texts were assessed for eligibility and finally, 41 articles were selected. The topic of target studies were categorized as follow:

i) Studying diagnostic accuracy of high NC for prediction cardiometabolic risk factors $(n=21)$.

ii) Studying association between $\mathrm{NC}$ and cardiometabolic risk factors $(\mathrm{n}=33)$.

Some studies addressed both of these topics.

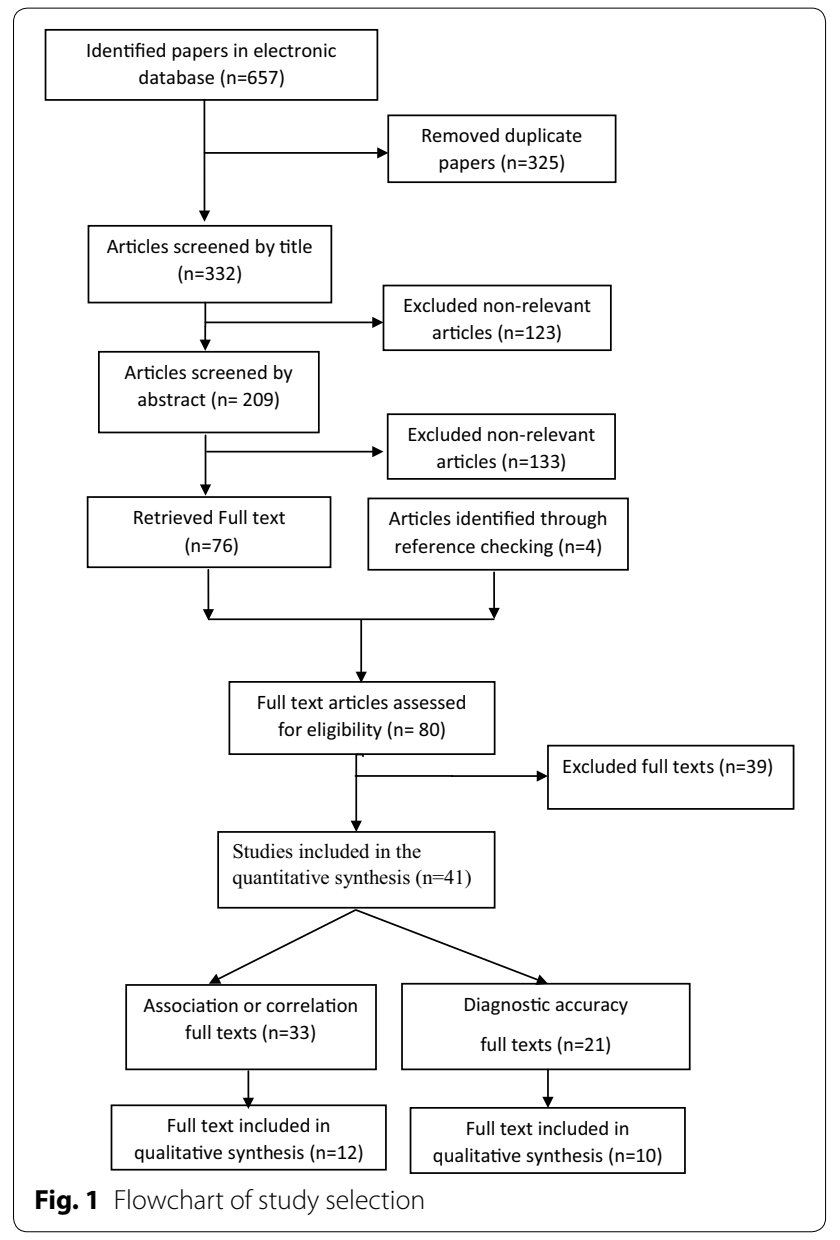

\section{Results of qualitative synthesis \\ A-1: The diagnostic accuracy of high NC to predict cardiometabolic risk factors}

A total of 21 articles (including 18 cross-sectional and 3 case-control studies) had reported SE and SP of NC for prediction of cardiometabolic risk factors. They were published between 2010 and 2016 in different countries: China $(\mathrm{n}=4)$, Brazil $(\mathrm{n}=3)$, USA $(\mathrm{n}=3)$, India $(\mathrm{n}=3)$, and 1 article in Colombia, Ukraine, Europe, Turkey, Canada, and Egypt. Eleven studies included children and adolescents and the other 10 ones assessed adults (Table 1).

The highest SE values of NC for prediction of MetS was 100 in children and 80 in adults. The maximum SP was 89.5 in children and 91 in adults. The SE values to predict overweight/obesity ranged from 34 to 97 in children, and the SP was between 50 and 94. Only 2 studies included adults $[9,10]$ wherein SE was between 62 and 87 in men, and 68 and 80 in women. SP was between 62 and 74 in men, and between 65 and 74 in women. In 2 studies which reported SE and SP of NC in the prediction of abdominal obesity $[10,11]$, SE ranged from 56.1 to 


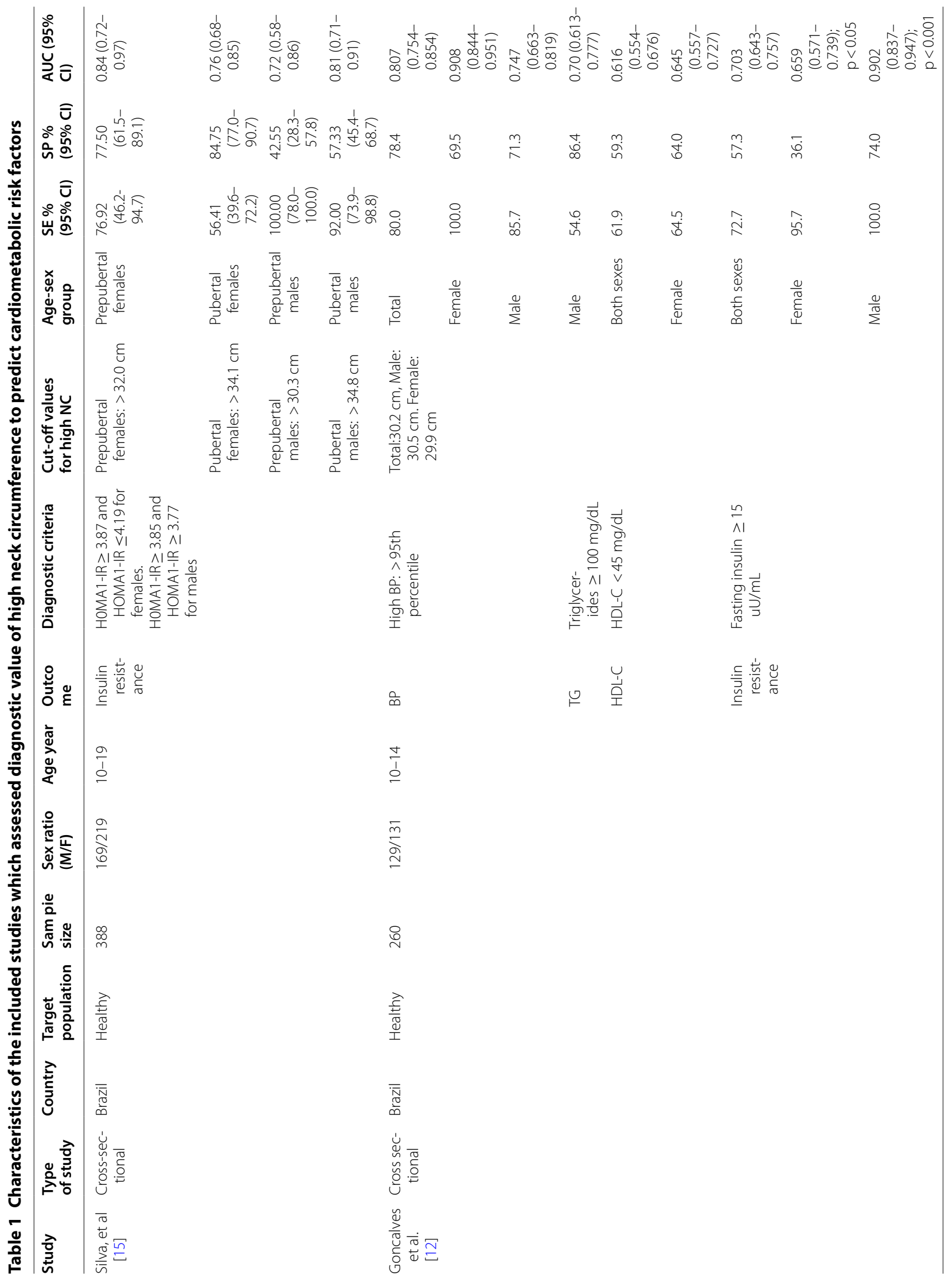









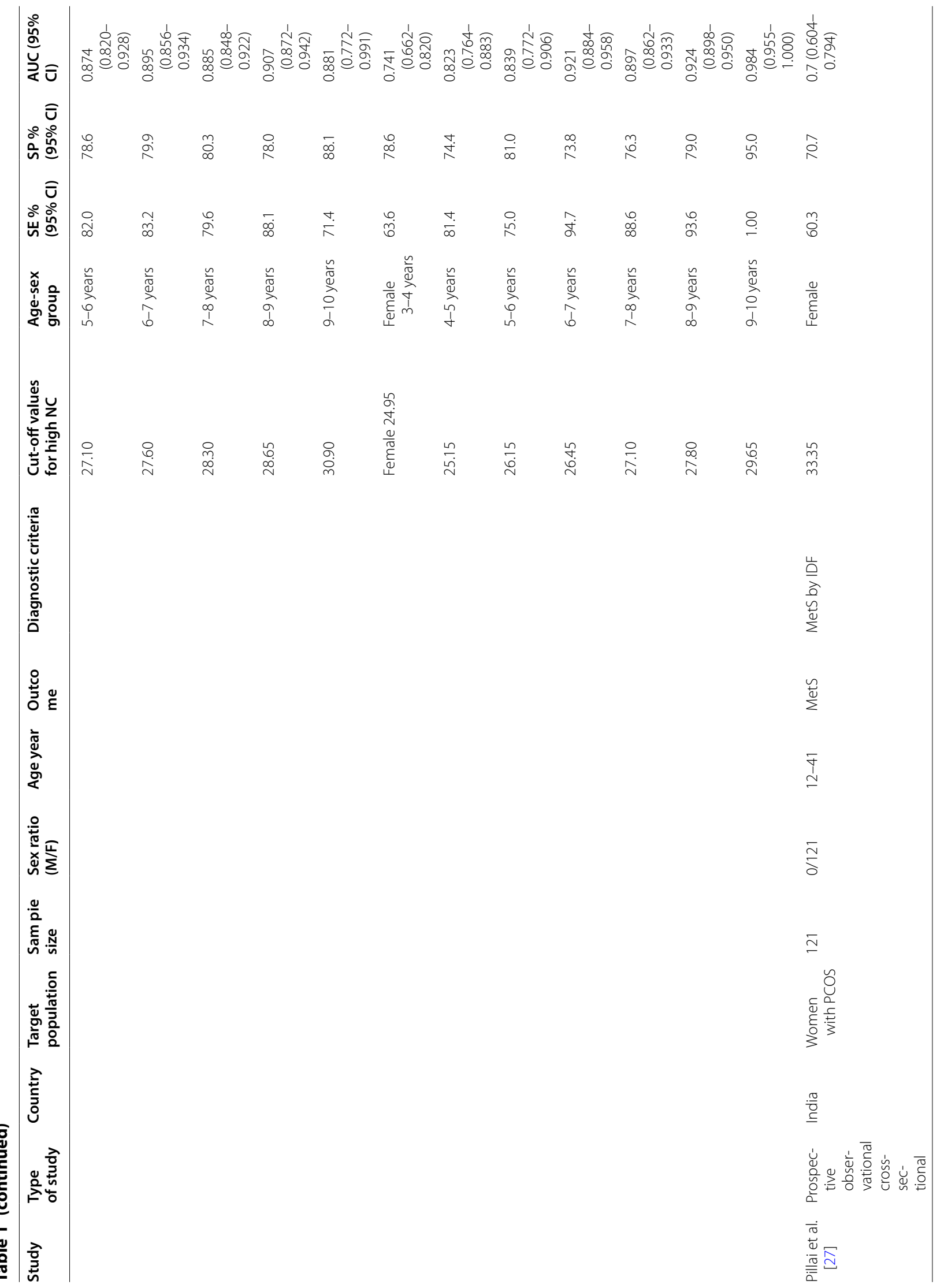




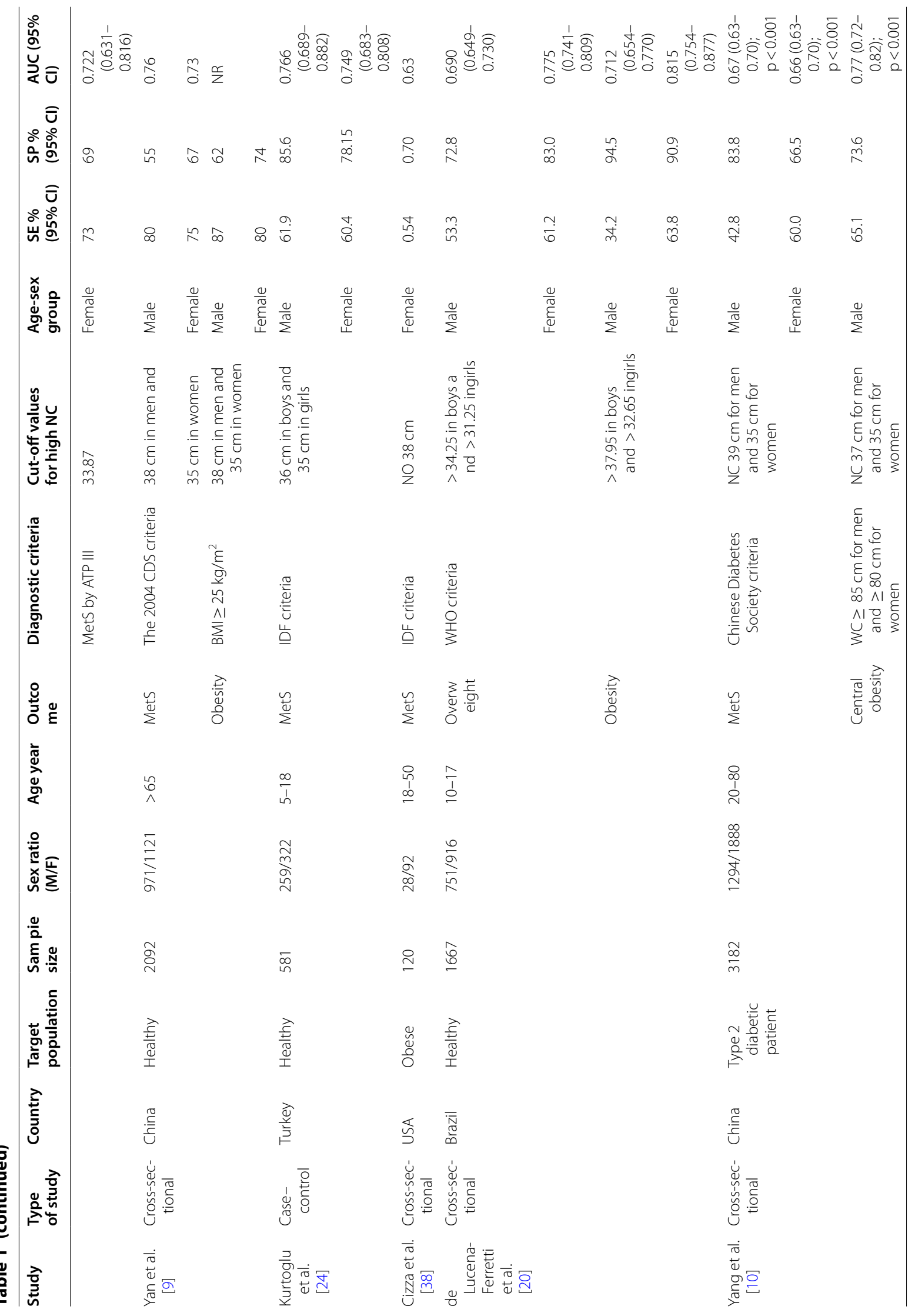









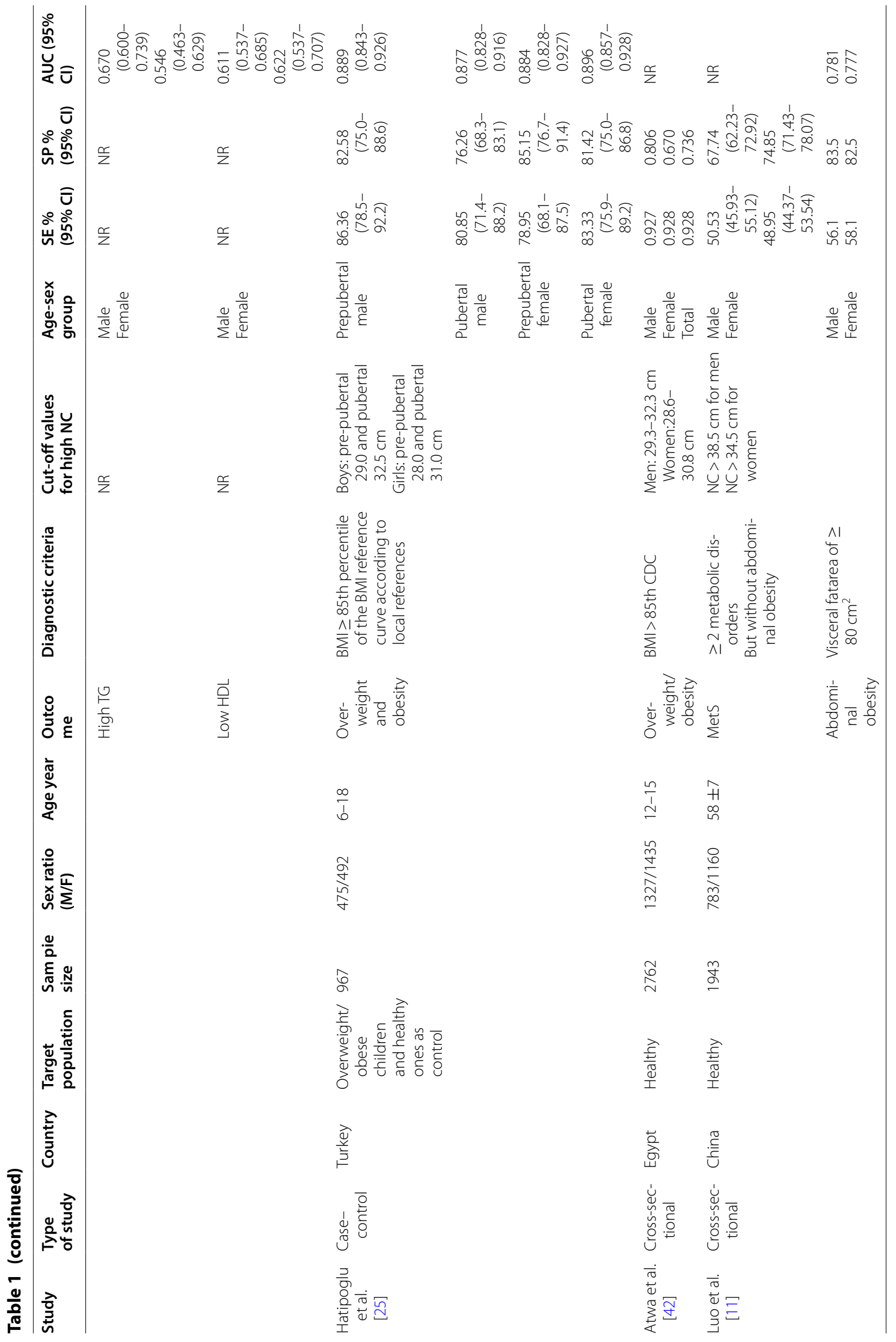




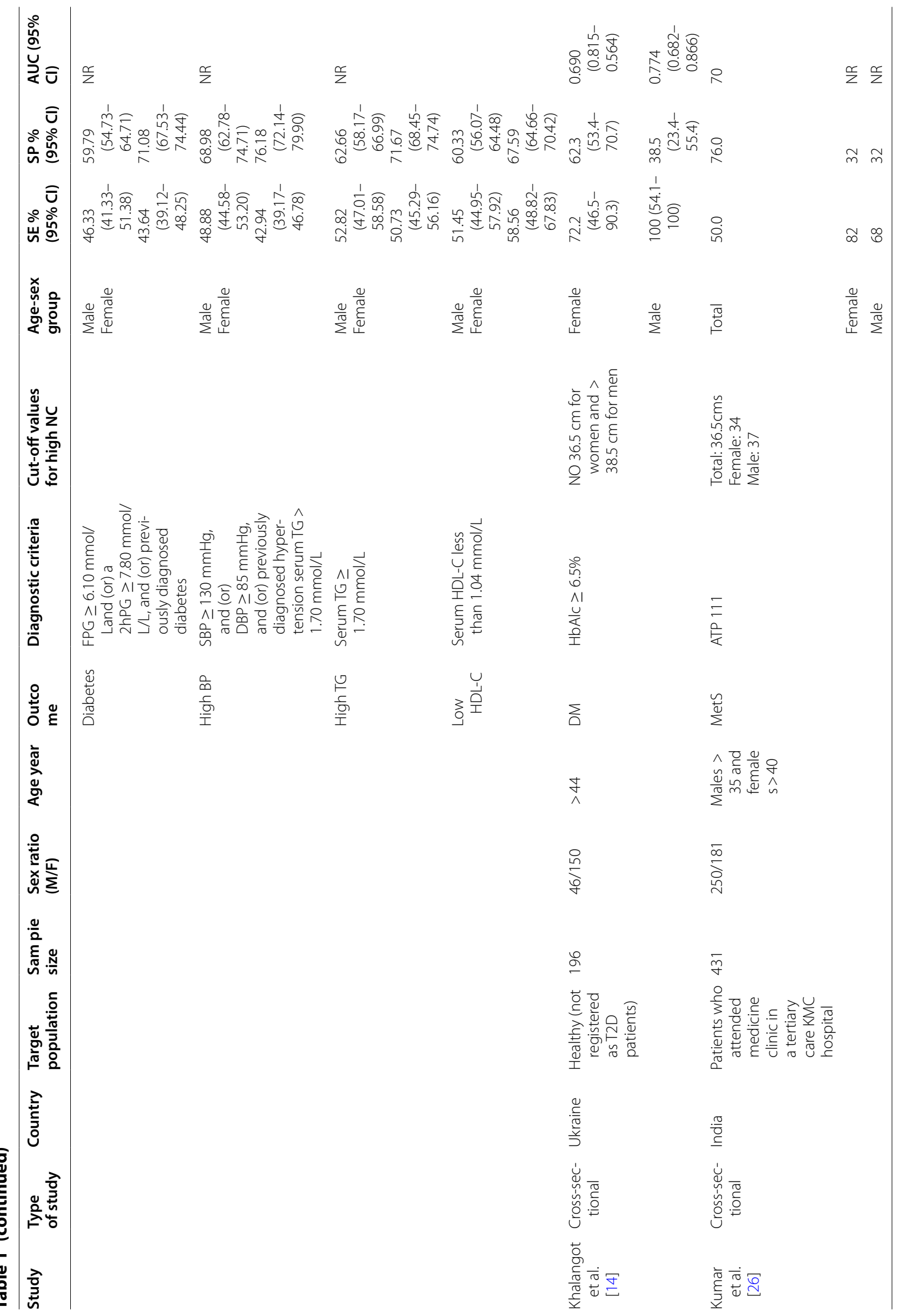




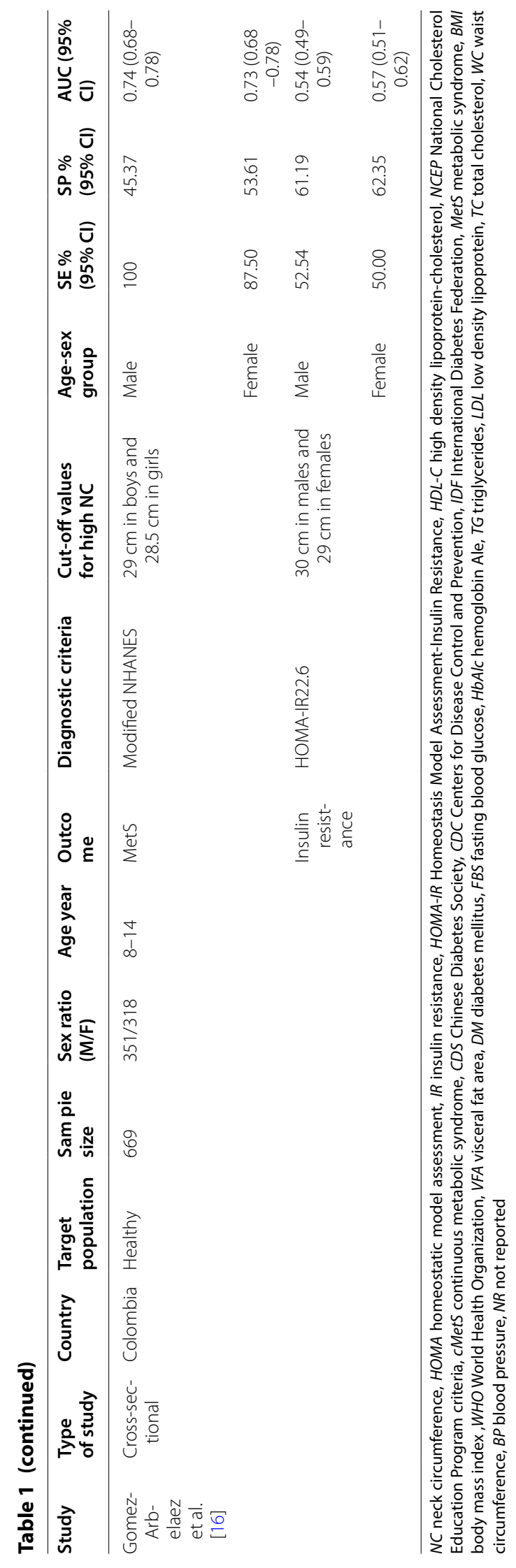


68.8 and SP ranged from 65.4 to 83.5. In 2 studies which reported SE and SP of NC for prediction of hypertension among children and adolescents, maximum SE and SP were 85 and 71 in boys and 100 and 69 in girls [12]. Only 3 studies assessed SE and SP of NC for the prediction of high TG and low HDL-C [11-13] wherein the highest values of SE and SP were 62 and 71, respectively.

Among 4 studies which assessed SE and SP of NC for prediction of type 2 diabetes [11-14], the maximum values of SE and SP was 80 and 67 in children [12], and 100 and 72 in adults. In studies which assessed insulin resistance $[12,15,16]$, two studies reported a SE of 100 in boys, and 50 to 95 in girls. The SP was 42 to 74 in boys, and 36 to 84 in girls.

According to QUADAS-2 checklist, the study methods of all diagnostic accuracy studies met all QUADAS-2 items. However, three studies were classified as "unclear risk" in the domain of "patient selection" (third question of the first domain) $[11,15,16]$. One studies were classified as "high risk" in the first question of the first domain (random sampling method) [9]. Totally, $83.33 \%$ of the studies were considered as high quality (low risk of bias) and $91.66 \%$ were classified as low concern according to the QUADAS-2 checklist.

\section{A-2: Association between NC and cardiometabolic risk factors} Articles which assessed association between NC and cardiometabolic risk factors were categorized into two sections: articles which assessed cardiometabolic risk factors as binary variables and reported odds ratio (OR) or relative risk (RR) in logistic regression analysis (Table 2), or articles which assessed cardiometabolic risk factors as continuous variables and reported correlation coefficient or Beta coefficient in correlation or linear regression analysis (Table 3).

Table 2 lists characteristics of studies reporting OR/ $\mathrm{RR}$ of high NC and the risk of cardiometabolic risk factors $(n=13)$. Most of them were designed as cross-sectional $(n=10)$ and the rest as case-control $(n=2)$ or cohort $(n=1)$. The studies were carried out in different countries including China $(n=3)$, Brazil $(n=3)$, Greece $(\mathrm{n}=2)$, and one study in Ukraine, USA, Iran, Lithuania, and South Korea. In 6 studies, children and adolescents were included, and 7 reports were on adult populations. The articles have been published between 2012 and 2017.

Three studies in adults assessed the OR of high NC in prediction of MetS presence [9, 17, 18]. Among them, Yan et al. found the strongest association between high $\mathrm{NC}$ and MetS in both elderly men and women, with ORs of 11.53 and 7.69, respectively [9]. The association between high $\mathrm{NC}$ and DM was reported in few studies $[9,14,18,19]$ where in ORs or RRs varied between 1.26 (1.06-1.50) and 2.07 (1.06-4.03).
Three studied reported the association between high $\mathrm{NC}$ and obesity. Among children and adolescents, ORs was between 1.07 and 1.70 for the prediction of overweight, and 1.10 to 3.25 for prediction of obesity [20, 21]. Yan et al. found again a strong association between high $\mathrm{NC}$ and obesity among elderly men and women, with ORs of 26.26 and 17.16, respectively [9].

In two studies which assessed the association between high NC and high TG $[9,18]$, the ORs were between 1.16 and 3.06. In regard to high BP, Kuciene et al. [22] found that greater $\mathrm{NC}$ was associated with 4 times risk for hypertension. Among adults, Yan et al. [9] found OR of 2.41 and 4.37 in elderly men and women, respectively.

Table 3 shows association studies where both NC and cardiometabolic risk factors were reported continuous variables. A total of 27 studies were found (14 publications included children and adolescents, and 13 studies in adults). Most of them used correlation coefficients, and few ones used beta regression coefficients for statistical analyses. The articles were published between 2010 and 2017. The studies were carried out in different countries including China $(n=6)$, India $(n=4)$, USA $(n=3)$, Turkey $(n=3)$, Brazil $(n=2)$, Egypt $(n=2)$, Greece $(n=2)$, and one study in Iran, Canada, Europe, Colombia, and South Korea.

Out of 18 studies which assessed the correlation between NC and BMI, 11 articles included children and adolescents. Significant correlations were found between $\mathrm{NC}$ and BMI. The $r$ ranged from 0.38 [21] to 0.88 [12] in adolescents. In adults, $r$ ranged from 0.41 to 0.84 in men and women together.

There was a significant association between WC and $\mathrm{NC}$ in all 20 studies (13 reports in children and adolescents, and 8 studies in adults). The $r$ ranged from 0.318 [23] to 0.85 [24, 25] among children and adolescents. In adults, $r$-values was between 0.45 [26] and 0.75 [27].

Out of 18 studies which reported the correlation between NC and blood pressure, 9 publications were on children and adolescents. A wide range of $r$ was found; from 0.02 [28] to 0.62 [12]. In some studies, the correlation was not significant $[13,28,29]$.

Weak correlations was observed between NC and FBS in 12 relevant studies, $(r$ ranged from -0.377 to 0.27 [29, 30]). Eleven studies also reported correlation between fasting insulin, HOMA-IR or both with NC. The $r$-values for these two variables were very close, ranging from 0.21 to $0.61[24,30]$.

Fourteen studies reported correlation coefficients of blood TC, TG, HDL-C, or LDL-C with NC. Findings of correlation between $\mathrm{TC}$ and $\mathrm{NC}$ was not conclusive; $r$-values ranged from -0.27 [12] to 0.302 [24]. Blood TG was positively correlated with $\mathrm{NC}$ in all reports $[r$ ranged from 0.06 [12] to 0.409 [24]. There was negative 


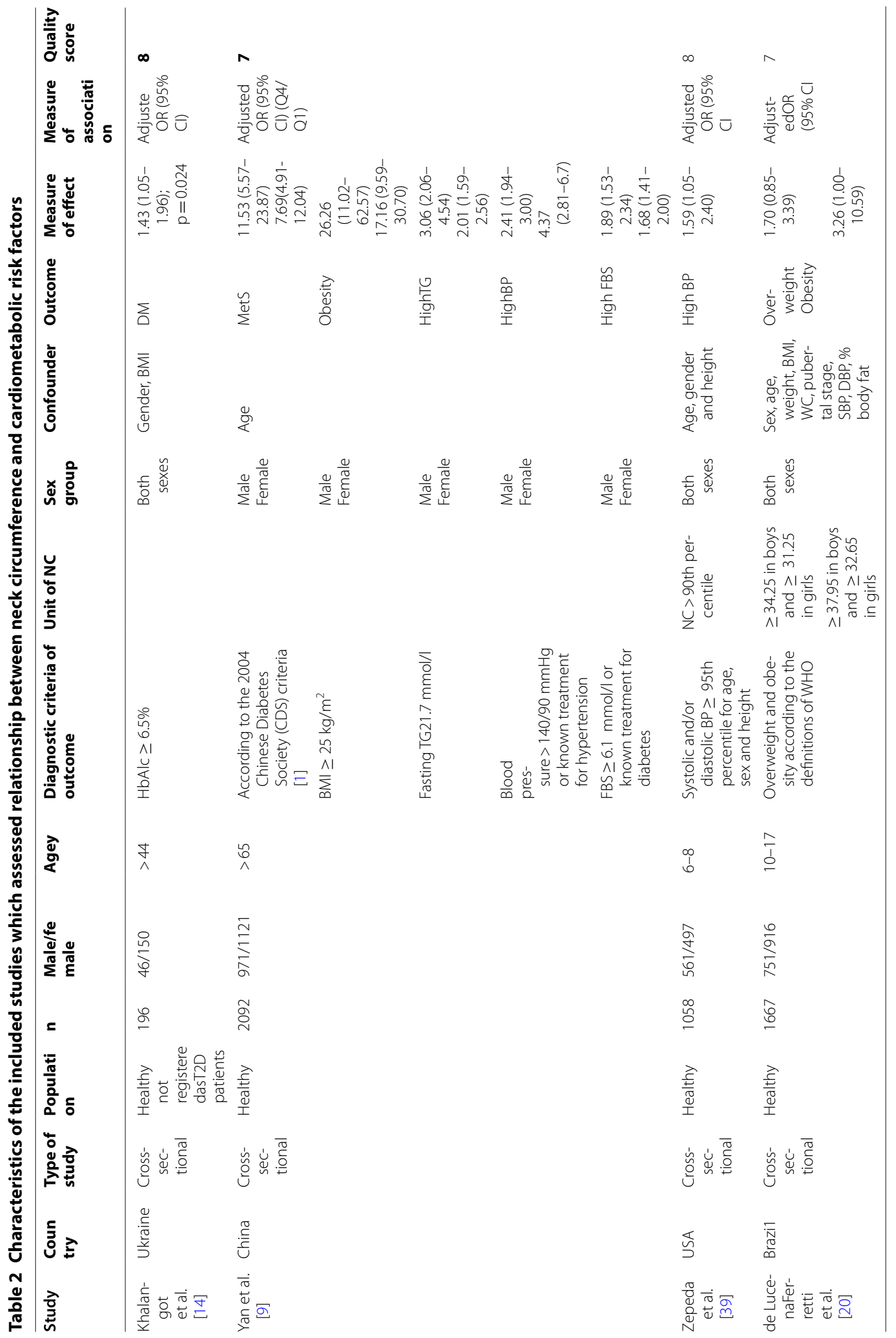




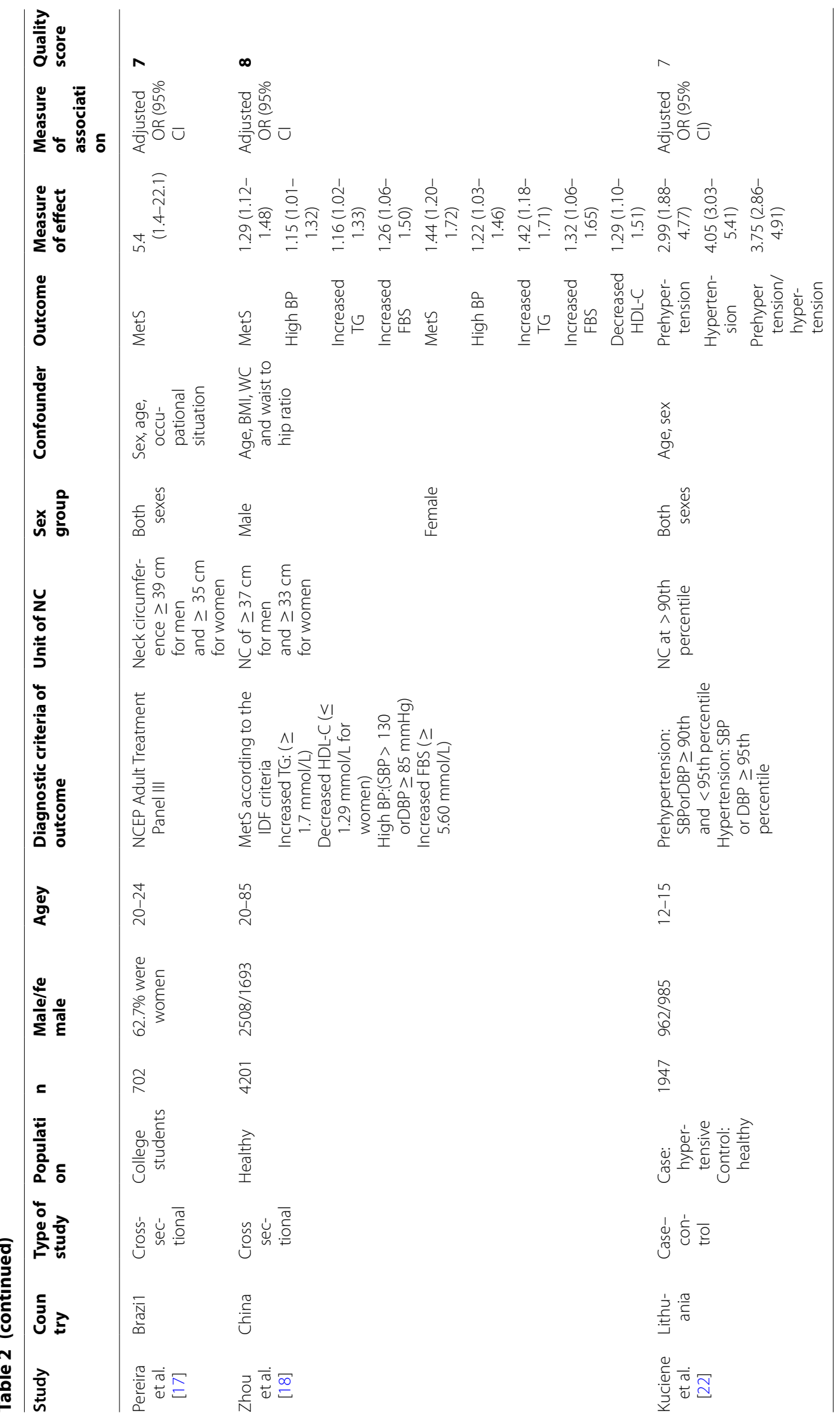









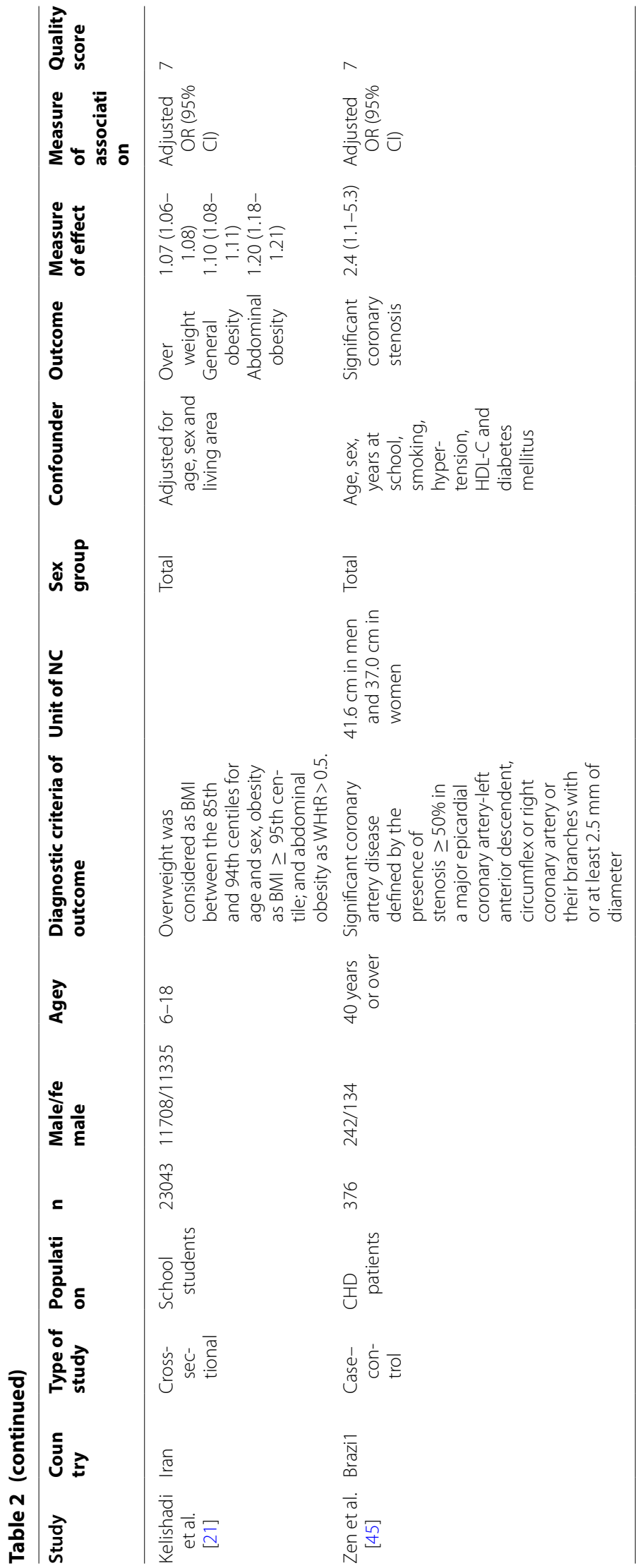




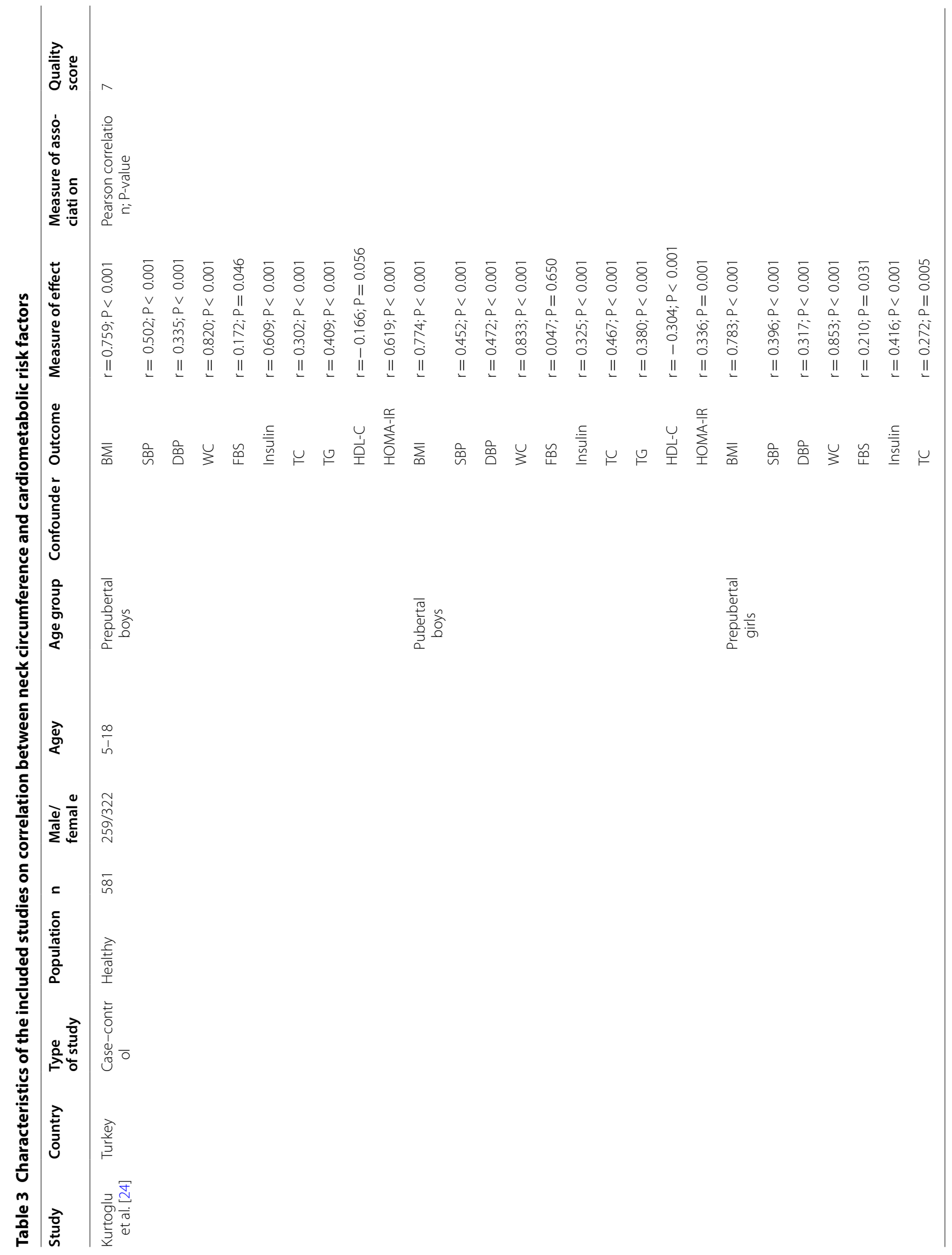




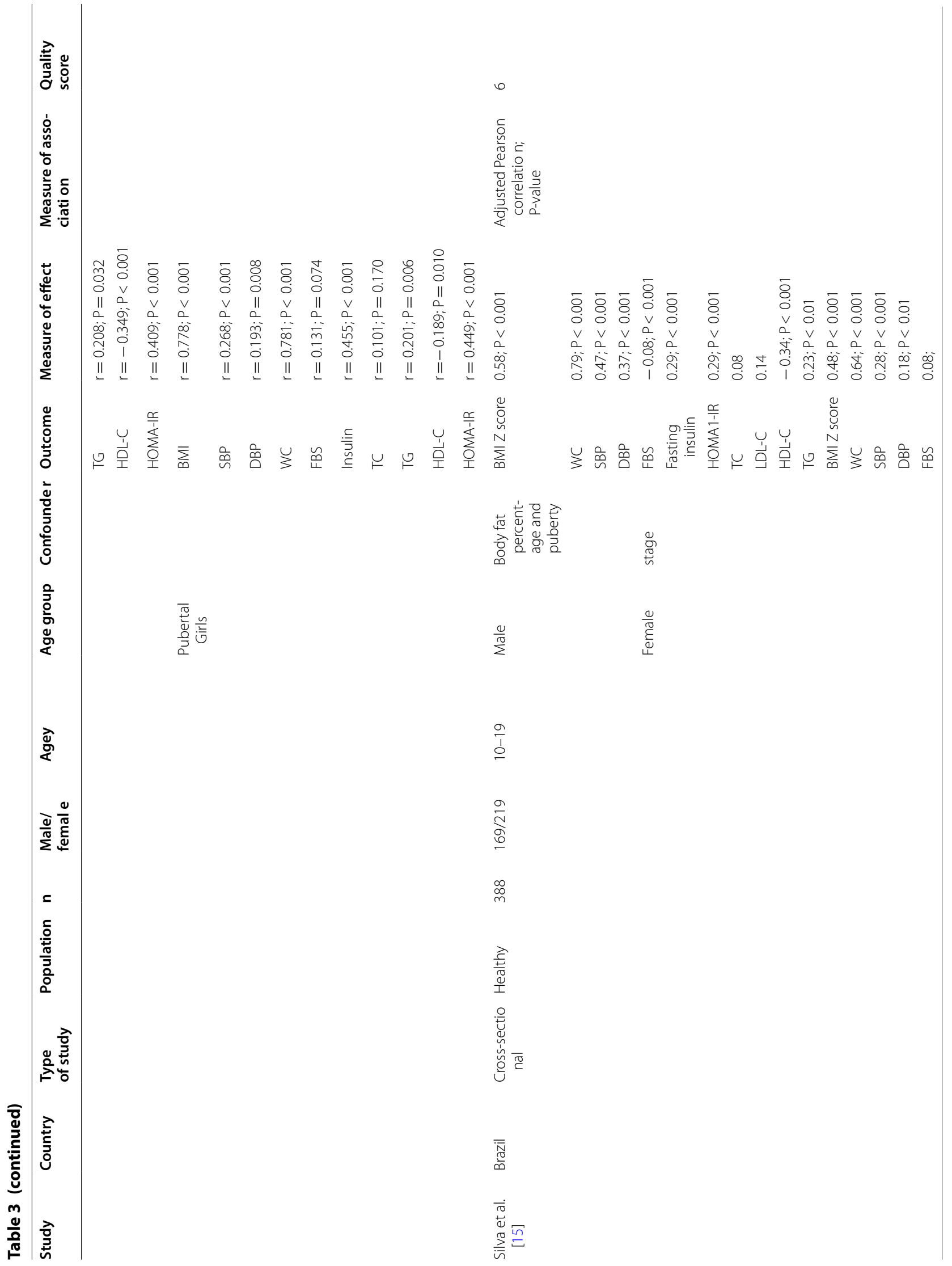




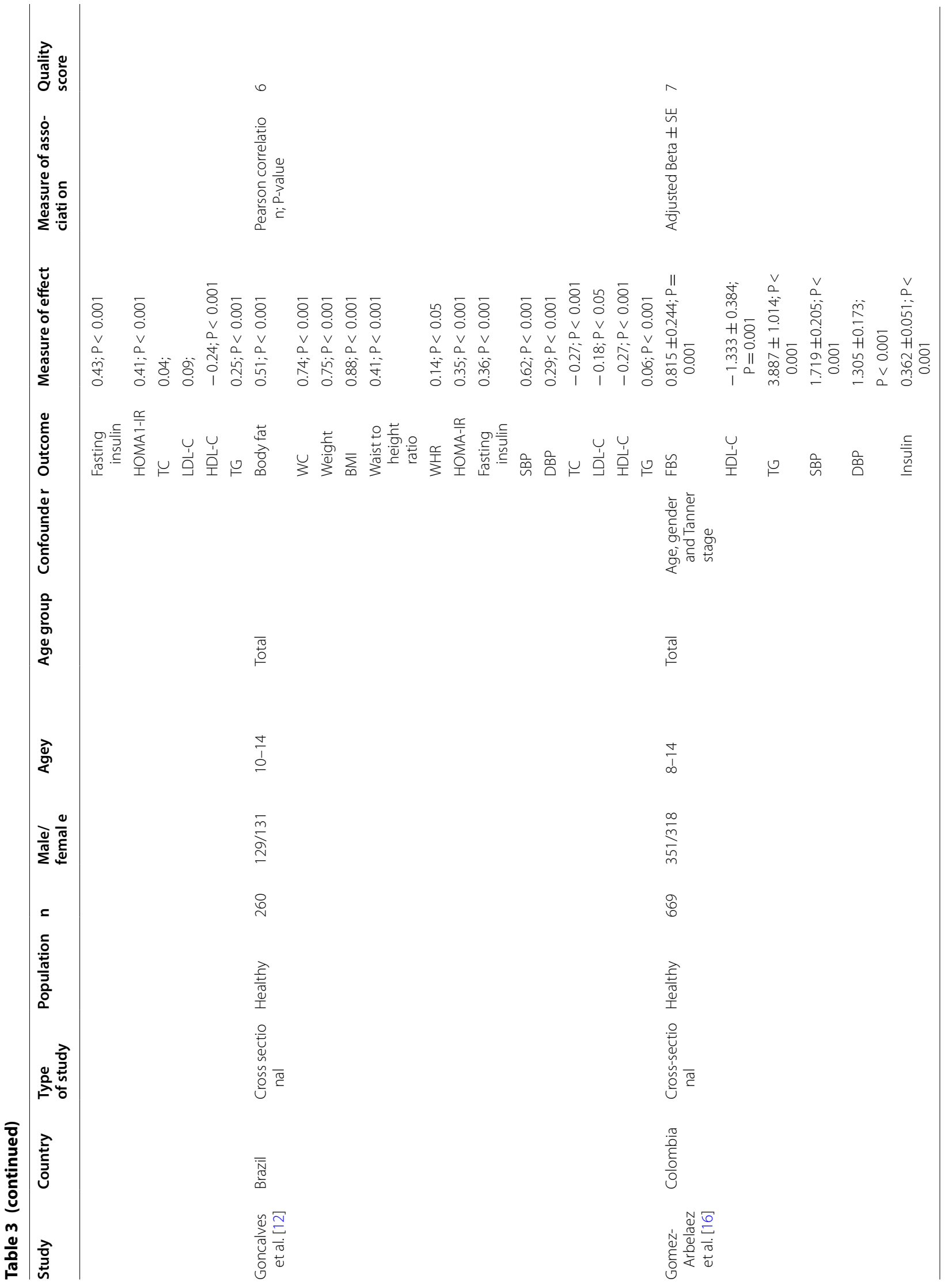




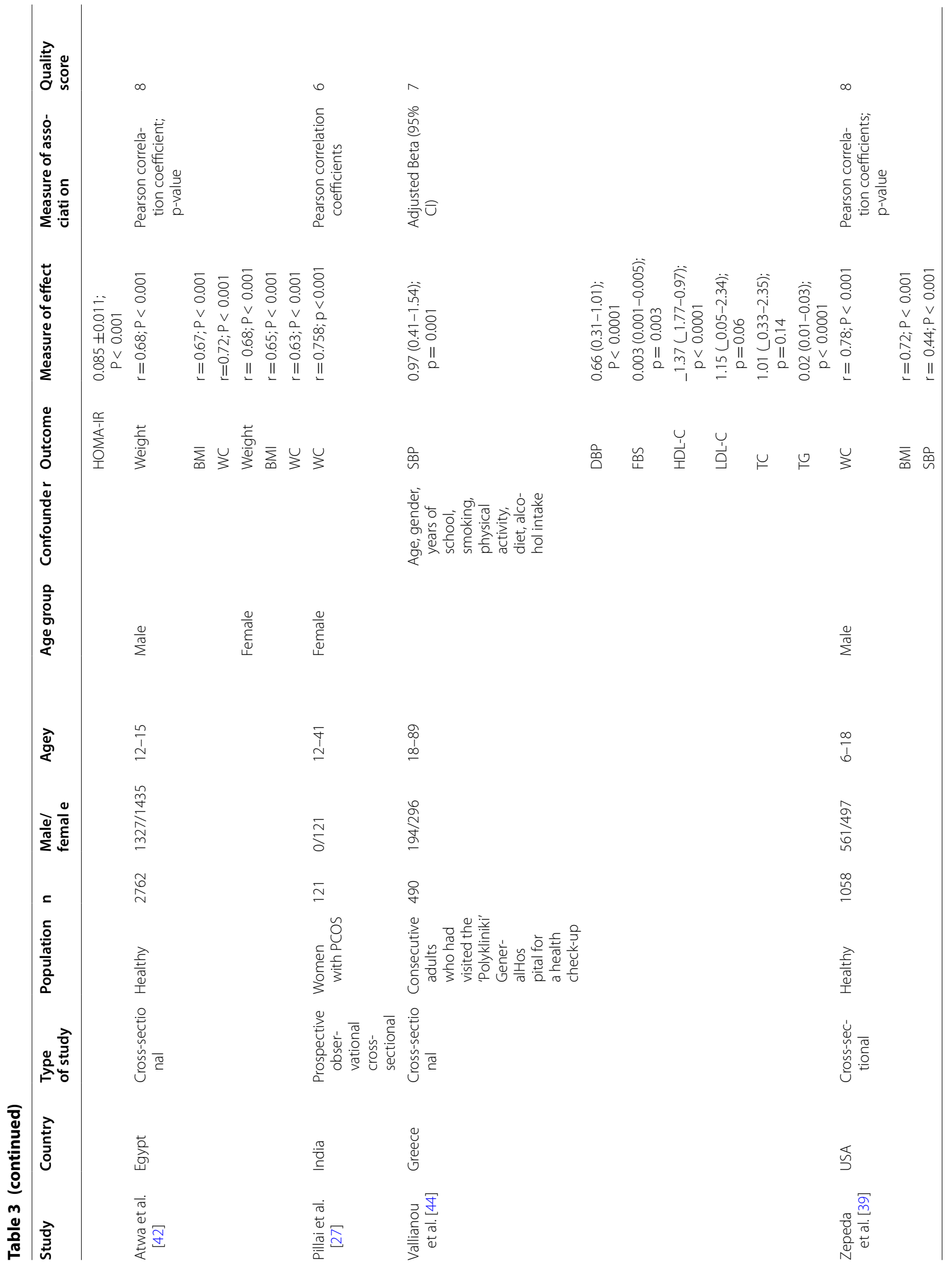




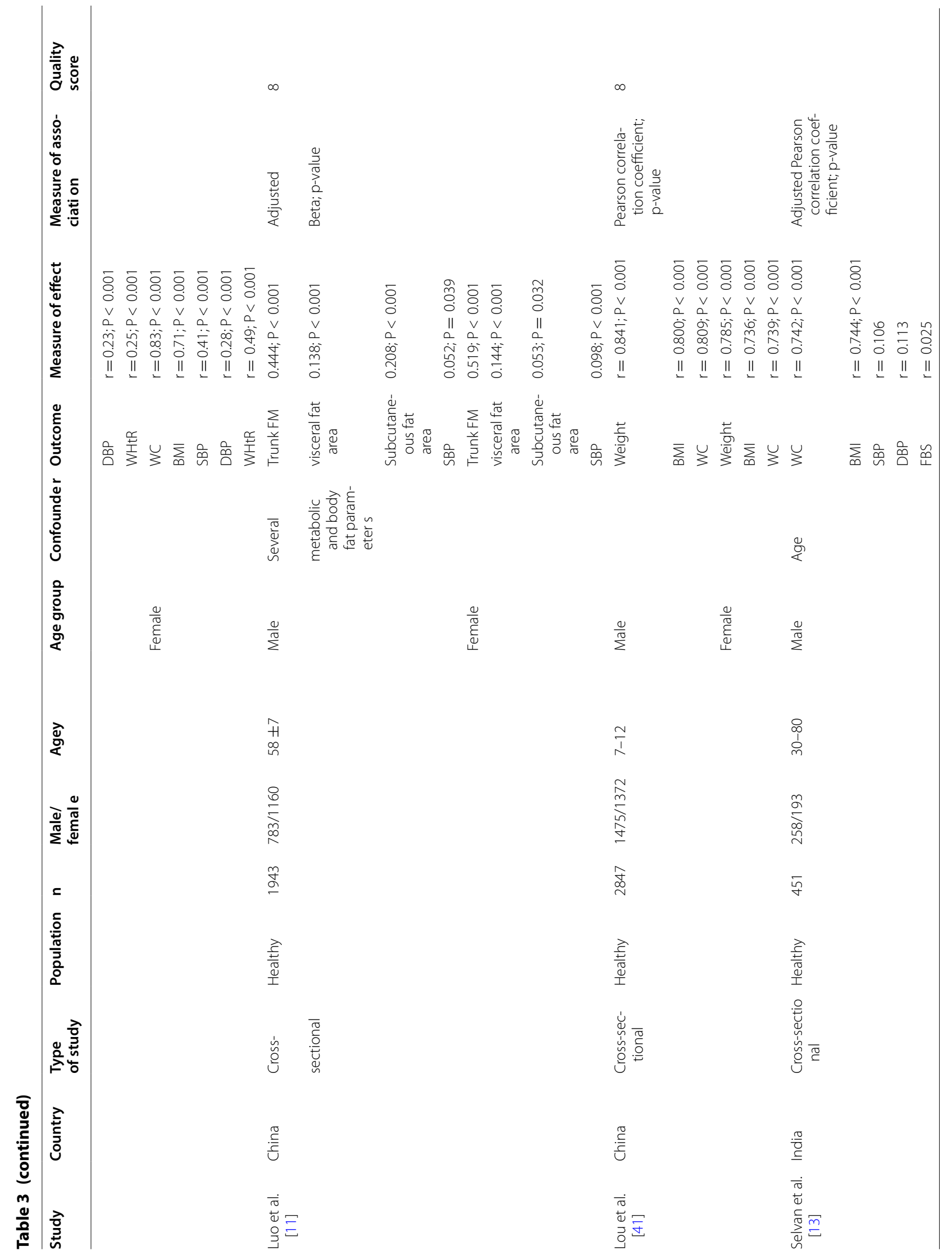




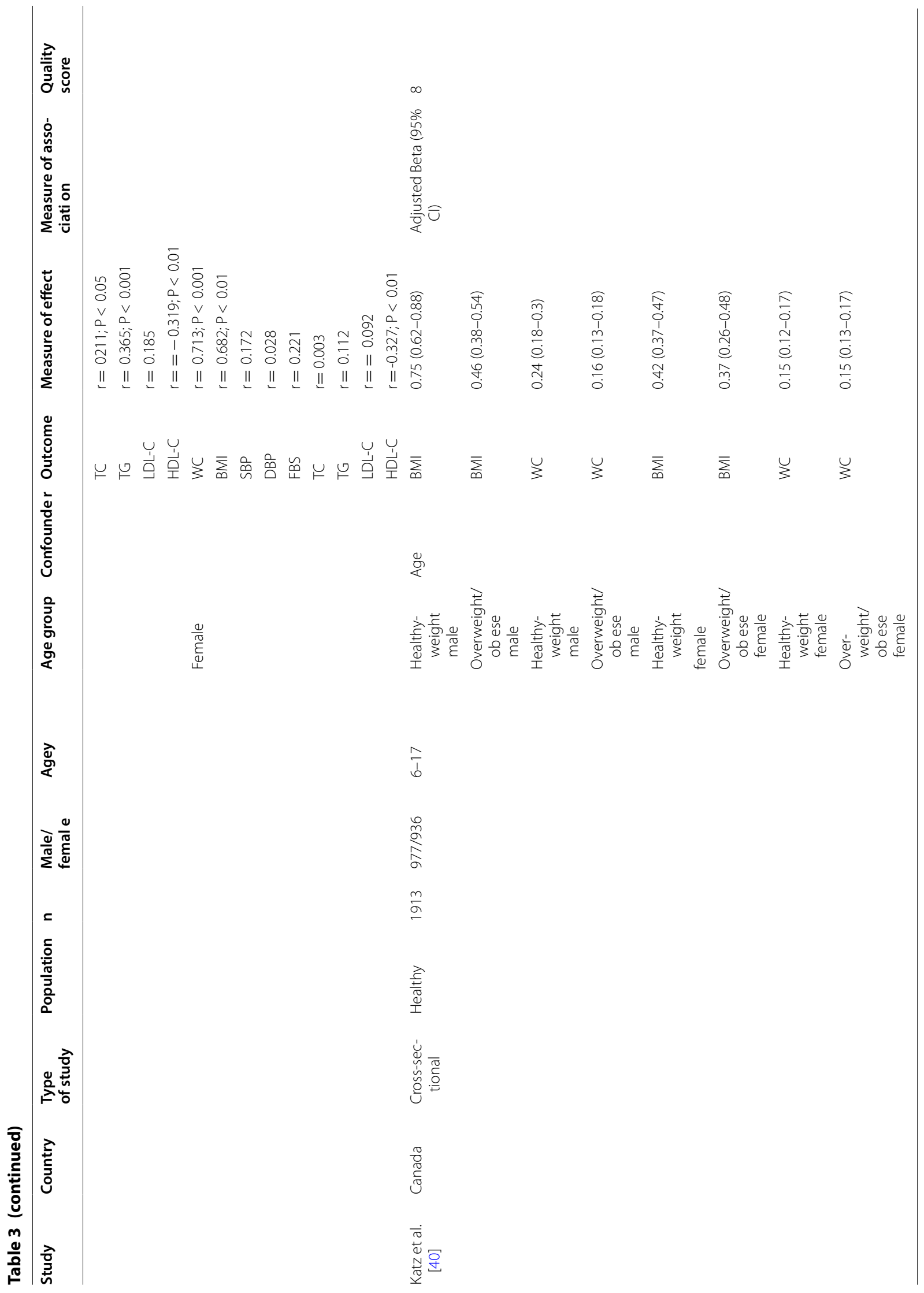




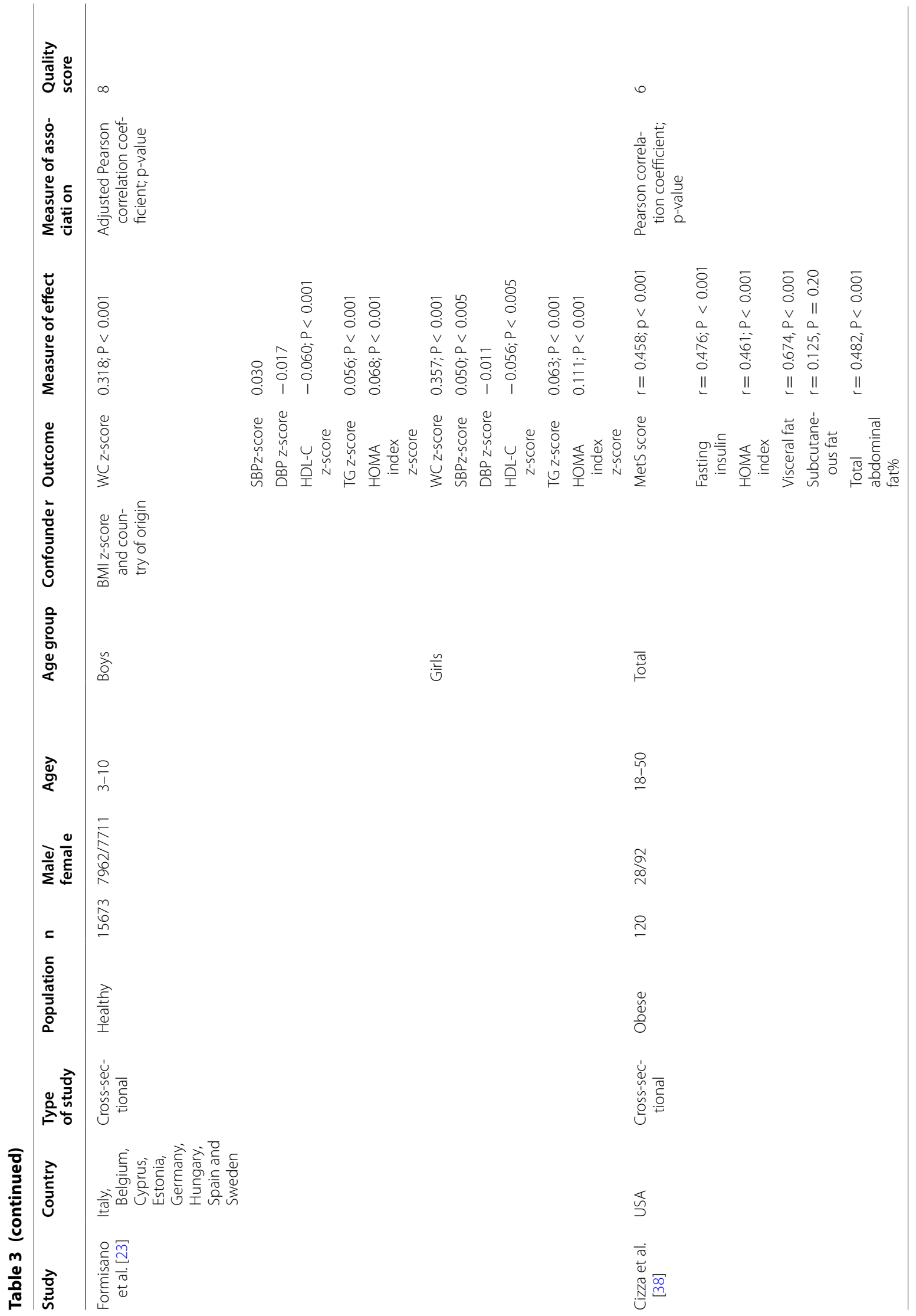




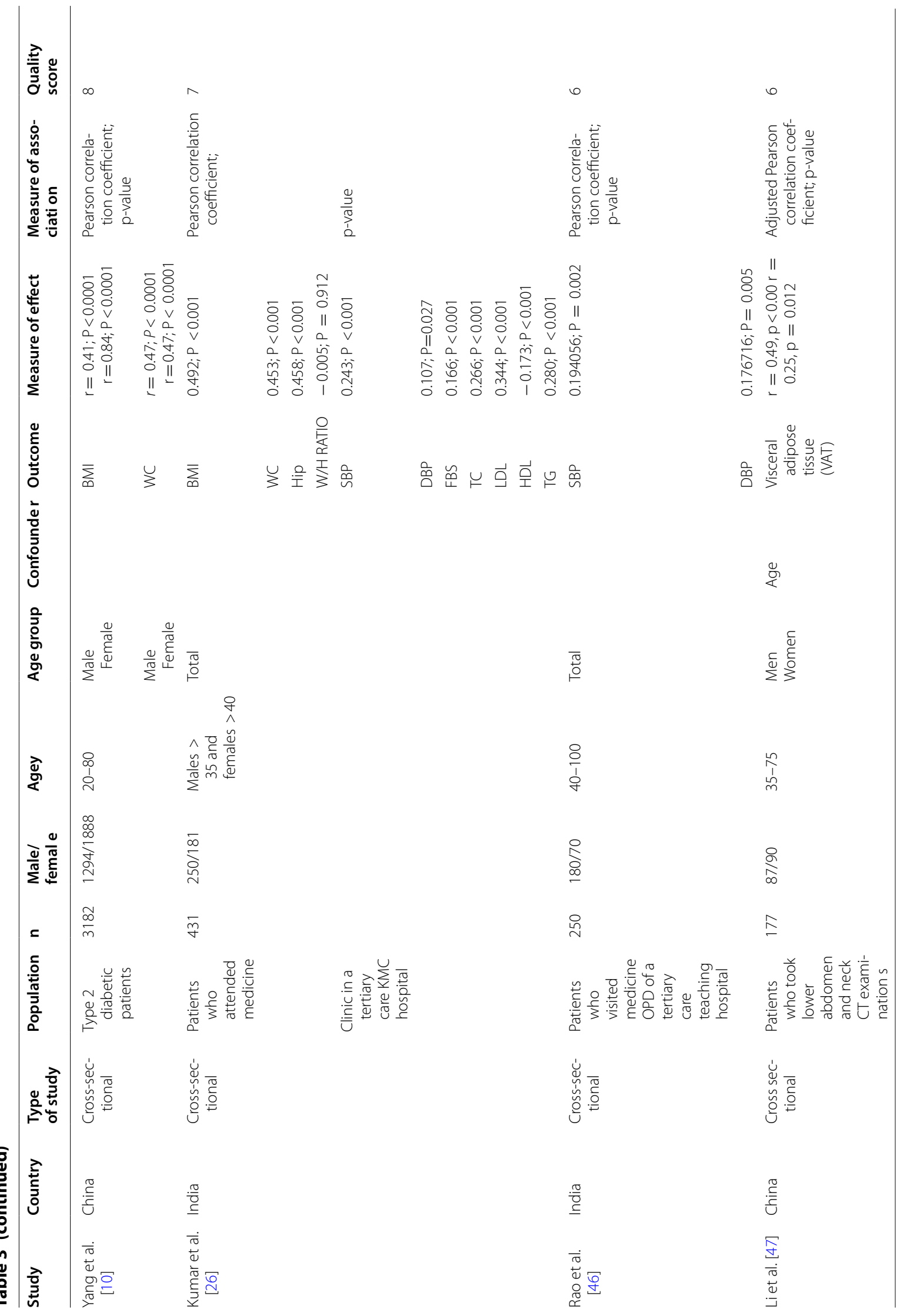









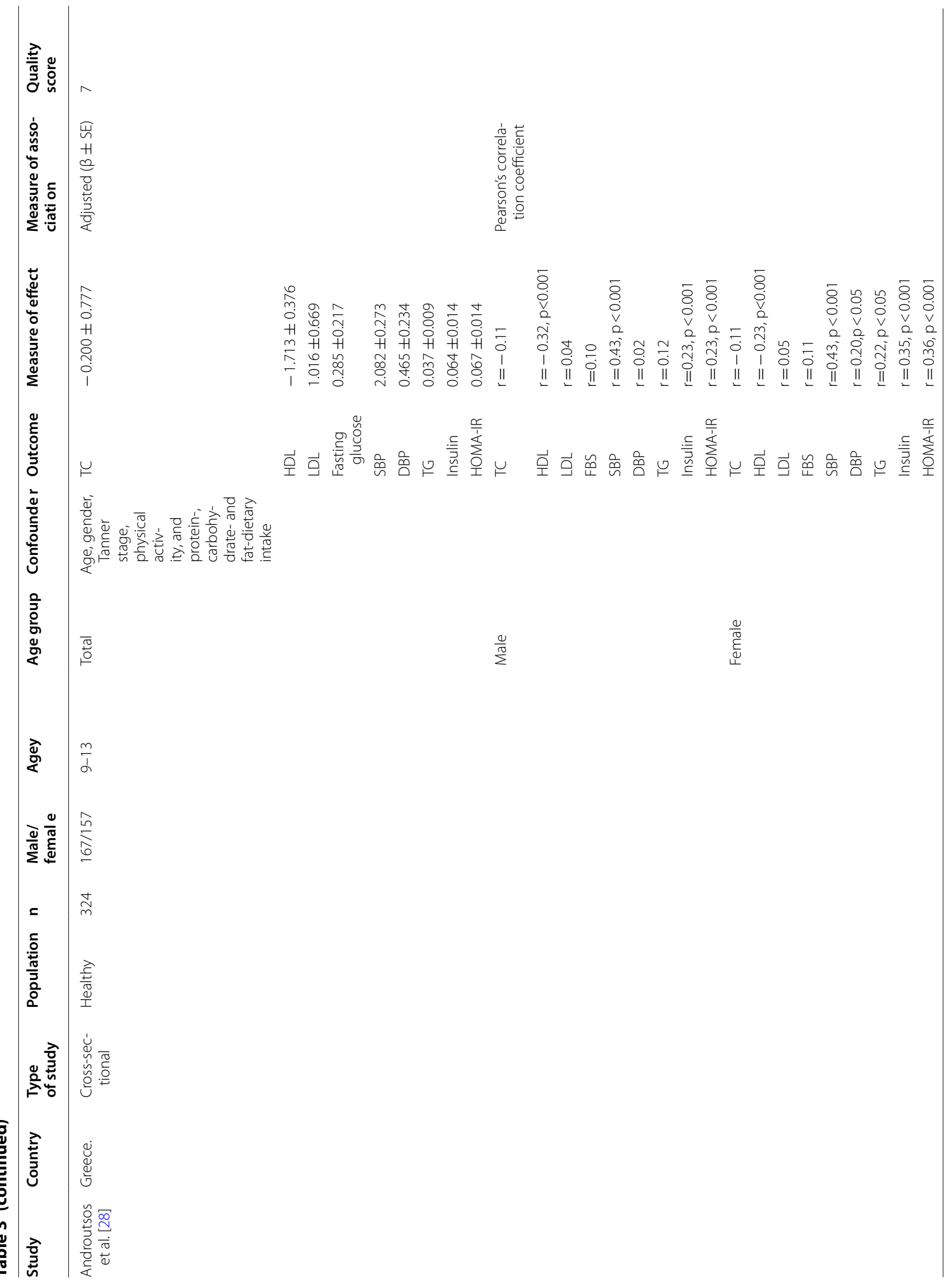




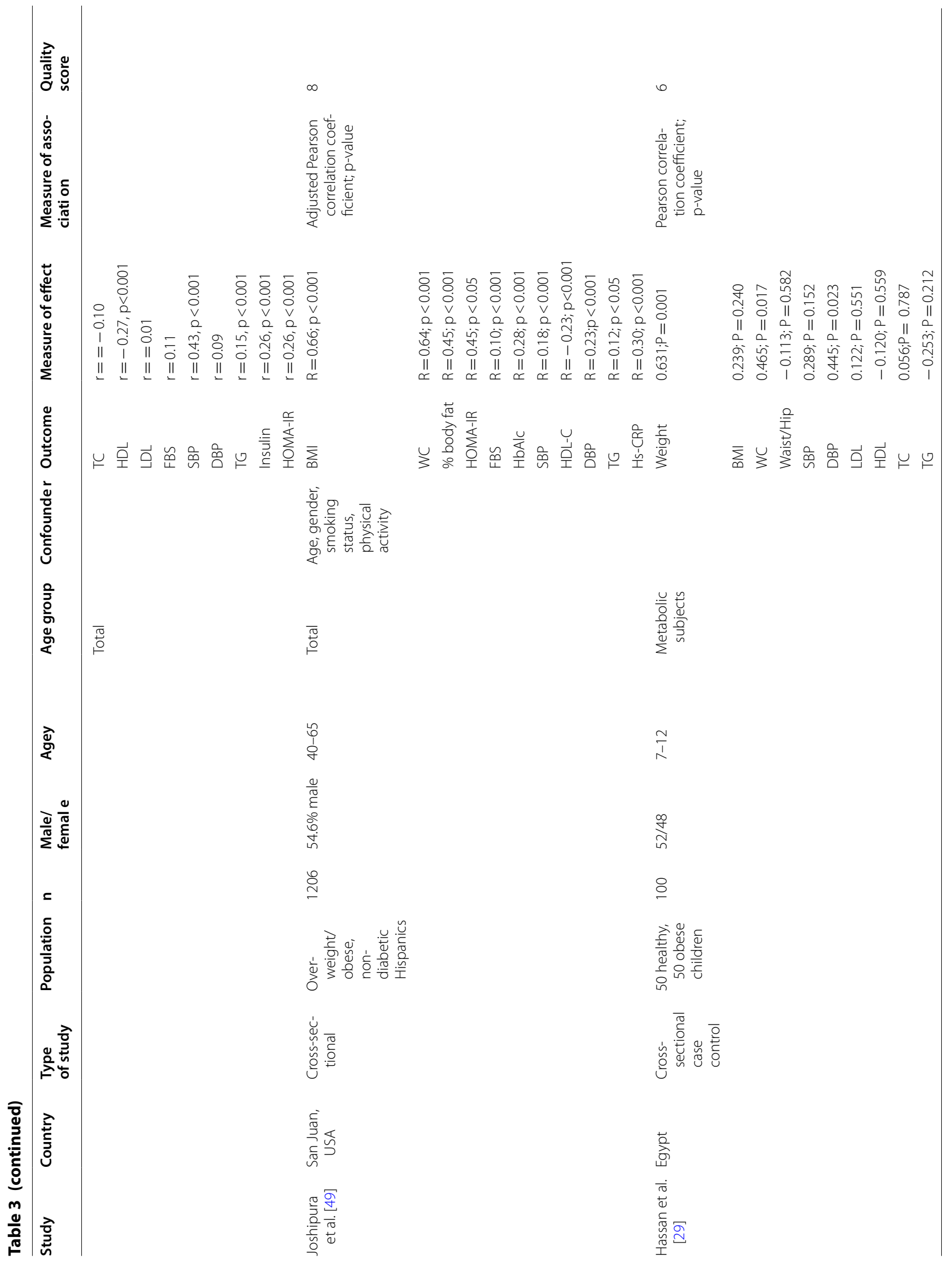




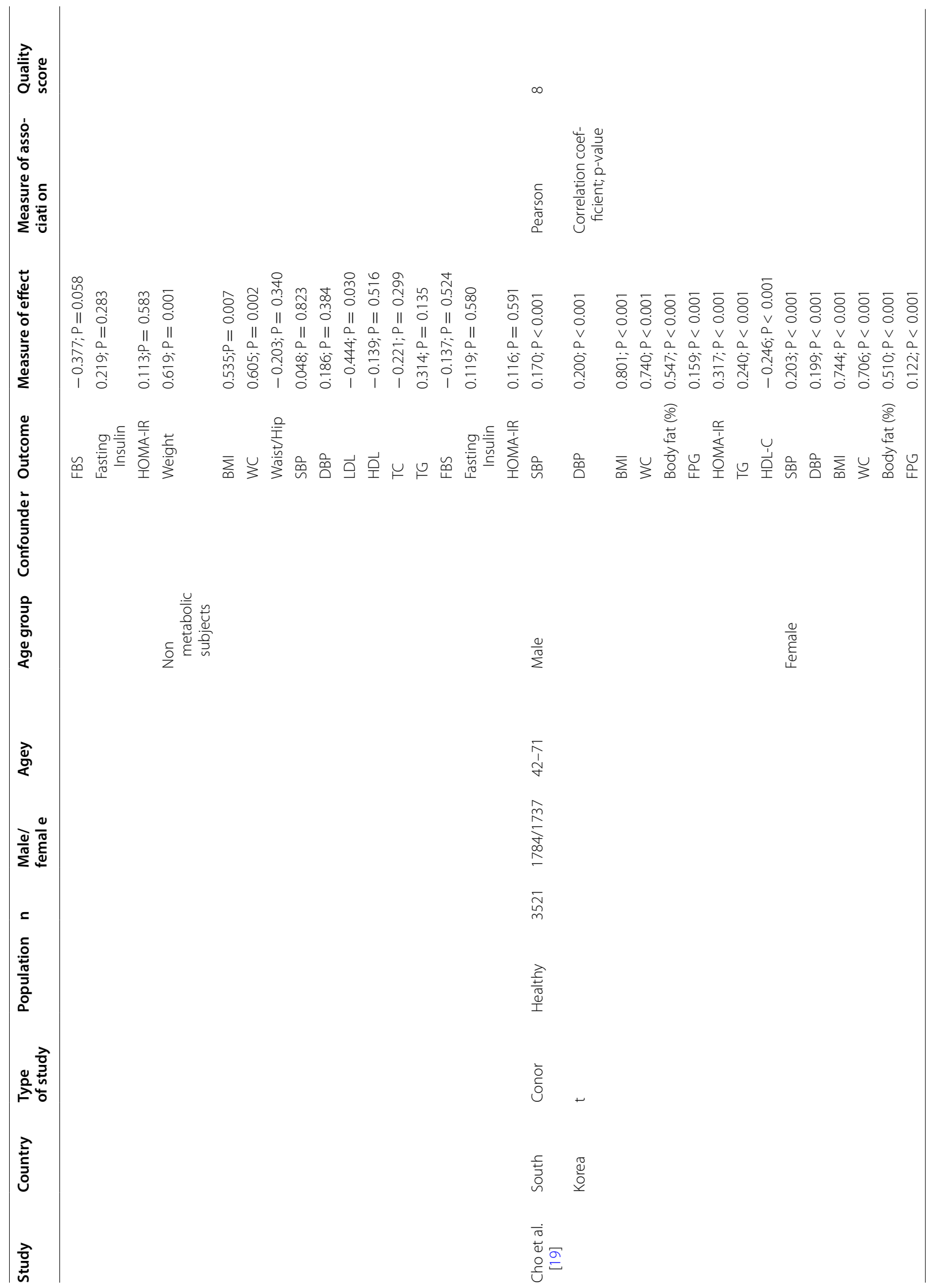




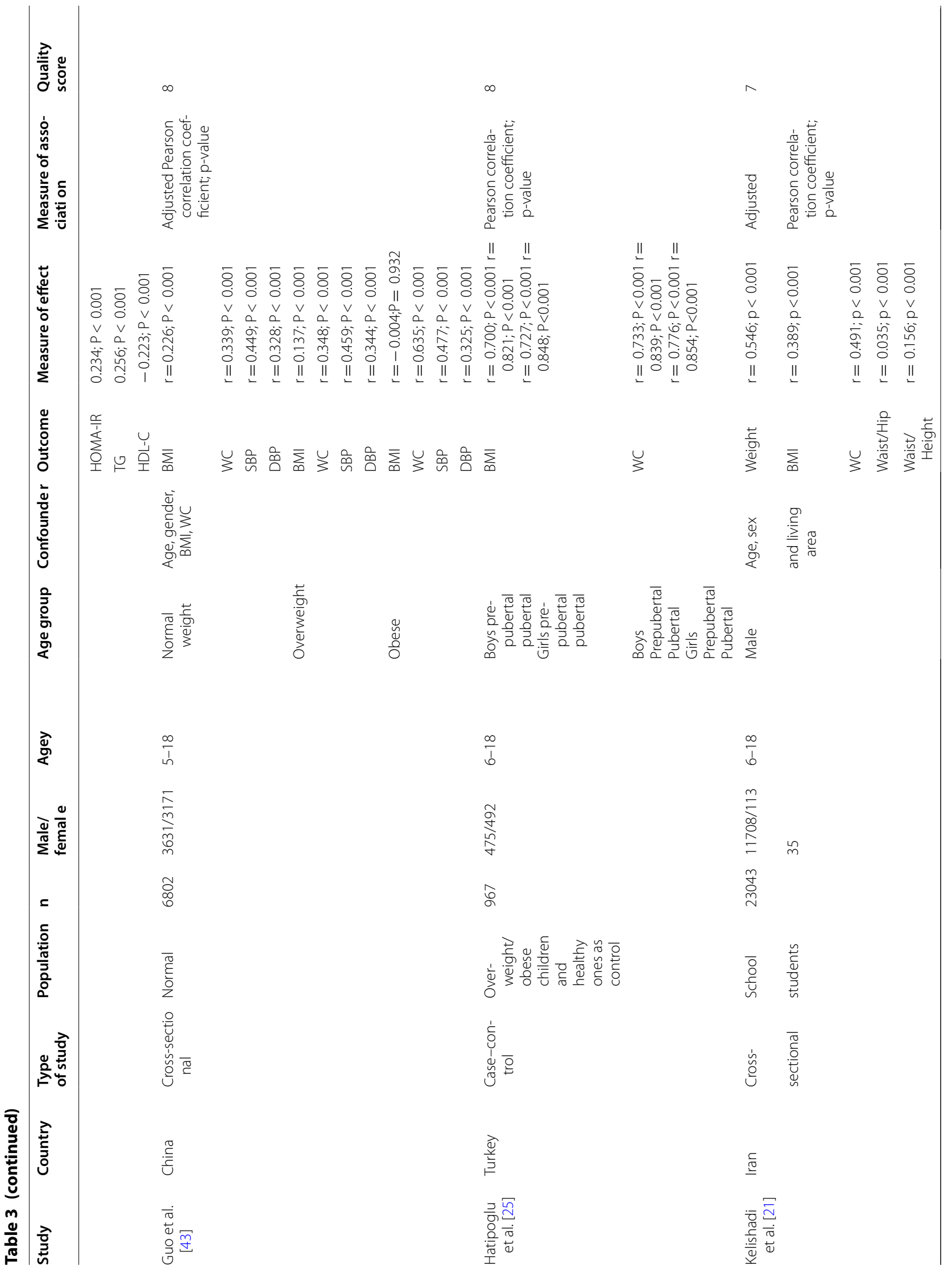




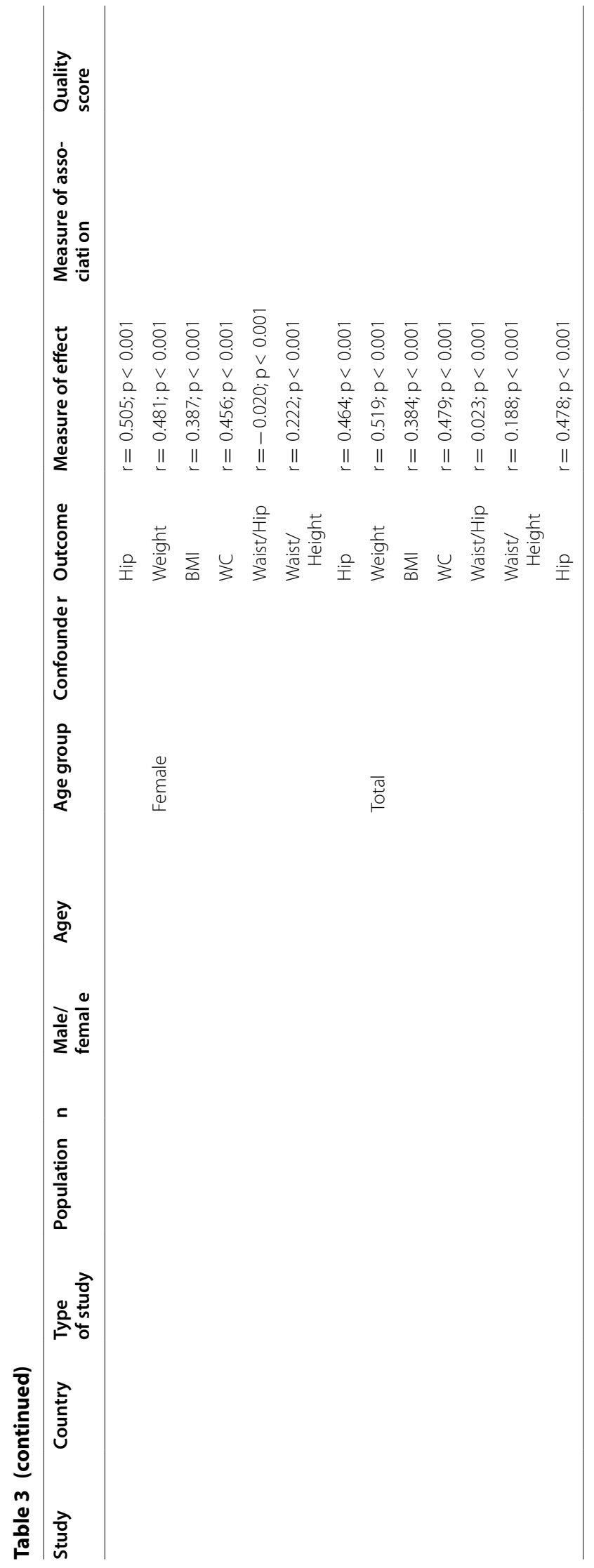


correlation between HDL-C and NC in all relevant publications, with $r$ ranging from -0.120 [29] to -0.35 [30]. Weak and mostly not significant correlations between LDL-C and NC were observed.

According to the Newcastle-Ottawa checklist, all selected studies were categorized as high quality study and attained score $\geq 6$ according to this scale. Overall, $20 \%$ of studies attained 6 scores, $38 \%$ of studies attained 7 scores and the rest got the score of 8 (Tables 2 and 3 ).

\section{Results of quantitative synthesis}

\section{B-1: The diagnostic accuracy of high NC to predict MetS}

The results of heterogeneity statistics about the SE of high NC to predict MetS according to sex and age groups showed sever heterogeneity in SE existed between studies in male $\left(\mathrm{I}^{2}: 97.9 \%\right.$; $\mathrm{Q}$ test: $\left.335.85, \mathrm{p}<0.001\right)$, female $\left(\mathrm{I}^{2}: 91.1 \%\right.$; $\mathrm{Q}$ test: $\left.112.26, \mathrm{p}<0.001\right)$, pediatric $\left(\mathrm{I}^{2}: 91.1 \%\right.$; Q test: $33.75, \mathrm{p}<0.001)$, adult $\left(\mathrm{I}^{2}: 96.2 \%\right.$; $\mathrm{Q}$ test: 391.78 , $\mathrm{p}<0.001)$, and overall population $\left(\mathrm{I}^{2}: 96 \%\right.$; $\mathrm{Q}$ test: 479.02 , $\mathrm{p}<0.001$ ). Due to sever heterogeneity between studies, the random effect meta-analysis was used and the pooled SE in male, female, pediatric, adult and overall population was estimated 69\% (95\% CI 56-83), 67\% (95\% CI 60-74), 77\% (95\% CI 55-99), 65\% (95\% CI 58-72) and $67 \%$ (95\% CI 61-74), respectively (Additional file 1: Figure S1:A-D). The results of heterogeneity statistics for SP of high NC to predict MetS indicated sever heterogeneity among studies in both sexes and age groups. The random effect meta-analysis showed that the pooled SP in male, female, adult, pediatric and overall population was $64 \%$ (95\% CI 52, 75), 67\% (95\% CI 60, 74),66\% (95\% CI 60, 72), $66 \%(95 \%$ CI 48, 84) and 66\% (95\% CI 60, 73), respectively (Additional file 2: Figure S2: E-H).

Publication bias: Begg's test confirmed no publication bias for sensitivity $(p=0.32)$ and specificity $(p=0.92)$ of high NC for predicting MetS.

\section{B-2: The association of NC with glycemic indices in adult populations}

FBS: The pooled estimates of 4 studies (seven effect sizes) indicated that there was a significant positive correlation between NC and serum levels of FBS (CC: 0.16, 95\% CI $0.13,0.20)$. However, the heterogeneity was high $\left(\mathrm{I}^{2}\right.$ : $56.0 \%, p=0.03$ ) (Additional file 3: Figure S3:1). Subgroup analysis based on age, sex and continent are presented in Additional file 4: Table S1. After stratification by continent (Asian, Non-Asian), we found that the association between NC and FBS concentrations in Asian population (CC: $0.19,95 \%$ CI 0.16, 0.22; $\mathrm{I}^{2}: 0, \mathrm{p}=0.61$ ) was stronger than Non-Asian (CC: $0.13,95 \%$ CI 0.10, 0.16; I ${ }^{2}: 28.3 \%$, $\mathrm{p}=0.24)$. This parameter attenuated the heterogeneity greater than gender subgroups.
HOMA-IR: The association between NC and HOMAIR was reported in three studies containing four effect sizes. The overall effect size showed a significant link between NC and HOMA-IR (CC: 0.38, 95\% CI 0.25, 0.50) in adult population, while the heterogeneity was high $\left(\mathrm{I}^{2}\right.$ : 93.5\%, $\mathrm{p}=0.0001$ ) (Additional file 3: Figure S3:2). Due to limited studies, it was not possible to perform subgroup analysis to find the reason of the heterogeneity.

\section{B-3: The association of NC with lipid profile in adult populations}

Based on the overall effect size, in subjects who had higher NC, serum levels of TC was higher than those with smaller one (CC: $0.12,95 \%$ CI 0.05, 0.19; $I^{2}$ : 79.2, $\mathrm{p}=0.001$ ) (Additional file 3: Figure S3:3). After stratification by age, a notable reduction was observed in the heterogeneity (Additional file 4: Table S1). Besides, pooling 8 effect sizes revealed that there was a significant correlation between NC and TG concentrations (CC: 0.23 , $95 \%$ CI 0.19, 0.28; I': 76.2\%, $\mathrm{p}=0.001$ ) (Additional file 3: Figure S3:4). However, after subgroup analysis the heterogeneity did not attenuate considerably (Additional file 4: Table S1). Meta-analysis on LDL-C concentrations also showed a positive association with NC (CC: $0.14,95 \%$ CI $0.07,0.22$ ); however, the heterogeneity was high $\left(\mathrm{I}^{2}: 79.2 \%, \mathrm{p}=0.001\right)$ (Additional file 3: Figure S3:5). Subgroup analysis showed that this association in men (CC: 0.13 , 95\% CI 0.03, 0.22; $\mathrm{I}^{2}: 59.1 \%, \mathrm{p}=0.11$ ) was stronger than women (CC: $0.08,95 \%$ CI $0.03,0.13 ; \mathrm{I}^{2}: 0 \%$, $\mathrm{p}=0.81$ )

Publication bias: Egger's test showed no publication bias for FBS $(p=0.49)$, HOMA-IR $(p=0.57)$, TC $(\mathrm{p}=0.92)$, TG $(\mathrm{p}=0.93)$ and LDL-C $(\mathrm{p}=0.25)$.

\section{B-4: The association of NC with glycemic indices in child populations}

FBS: From five studies in which the association between NC and FBS concentrations was reported, 12 effect sizes were extracted. The pooled estimates showed that children with greater NC had higher levels of FBS compared to those with smaller one (CC: $0.12,95 \%$ CI 0.07, 0.16; $\mathrm{I}^{2}: 48.4 \%, \mathrm{p}=0.03$ ) (Additional file 5: Figure S4:1). No severe heterogeneity was found for this association.

HOMA-IR: The correlation between NC and HOMAIR was reported in 6 studies including 11 effect sizes. Based on findings, greater NC was correlated with higher HOMA-IR (CC: 0.27, 95\% CI 0.23, 0.31). However, the heterogeneity was considerably high $\left(\mathrm{I}^{2}: 93.2 \%\right.$, $\mathrm{p}=0.0001$ ) (Additional file 5: Figure S4:2). 


\section{B-5: The association of NC with lipid profile in child populations}

The pooled estimates $(n=12)$ of five studies showed a significant positive link between $\mathrm{NC}$ and TC concentrations (CC: 0.07 95\% CI 0.02, 0.12; I $\mathrm{I}^{2}: 87.8 \%, \mathrm{p}=0.001$ ), although it was a weak correlation (Additional file 5: Figure S4:3). Findings of six studies also revealed a significant link between NC and TG levels (CC: 0.21, 95\% CI $0.17,0.25 ; \mathrm{I}^{2}: 61.2 \%, \mathrm{p}=0.001$ ) (Additional file 5: Figure S4:4). However, no correlation was obtained between NC and LDL-C (CC: 0.01, 95\% CI - 0.06, 0.07; $\mathrm{I}^{2}: 65.9 \%$, $\mathrm{p}=0.005$ ) (Additional file 5: Figure S4:5). Due to limited studies on children, subgroup analyses were not possible.

Publication bias: Begg's test confirmed no publication bias for FBS $(\mathrm{p}=0.19)$, HOMA-IR $(\mathrm{p}=0.38)$, TC $(\mathrm{p}=0.37)$, TG $(\mathrm{p}=0.58)$ and LDL-C $(\mathrm{p}=0.06)$.

\section{Discussion}

The current systematic review and meta-analysis revealed a positive association of NC, glycemic status and lipid profile in adult and child populations. However, no correlation was observed between NC and LDL-C concentrations in children. In general, due to high heterogeneity the findings should be declared with caution. Moreover, the association between NC and other cardio-metabolic risk factors were significant in most studies. However, because of limited studies drawing a certain decision needs further studies. Although the SE and the SP of $\mathrm{NC}$ to predict MetS were greater than about $65 \%$ in both child and adult populations, the between-study heterogeneity was considerably high.

To the best of our knowledge, the present study is the first study that examined the association of $\mathrm{NC}$ and cardio-metabolic risk factors in all age ranges and determined the SE and the SP of NC to predict MetS. In the present study, subgroup analysis revealed that the link between serum levels of FBS and NC in Asian was stronger than other adult populations. Findings on children populations also showed that the link between NC and FBS was significant only in Asian populations. Additionally, in Asian children the link between insulin resistance and $\mathrm{NC}$ was stronger than non-Asians.

These findings showed that race can play a main role in this correlation. Besides, the correlation between $\mathrm{NC}$ and LDL-C levels in men was stronger than the correlation in adult women. Therefore, gender can be another factor that affects the association. Energy intake, physical activity level, and menopause status are possible factors that can affect the link. In the present study, some included studies did not control such factors and it is likely to cause bias in the findings.

Another factor in the association between $\mathrm{NC}$ and cardio-metabolic risk factors is likely to be study design.
In the present systematic review, design in most studies was cross-section. The weakness of this kind of study is inability to clarify a cause and effect relationship. Prospective cohort studies can shed light on the type of the association.

Although prior studies introduced $\mathrm{WC}$ as a good predictor for cardio-metabolic risks [31, 32], it has some limitations. For instance, several sites including midway between rib cage and iliac crest, the lower border of rib cage, and iliac crest umbilicus are used for measuring WC. This resulted in different values for WC. Moreover, time of measurement, the state of expiration and fullness affect the measure [29, 33]. However, NC measurement is easy and accessible. Besides, a unit site for measurement was reported among the studies. NC is measured above the cricoid cartilage and perpendicular to the long axis of the neck $[34,35]$. Due to no variation in the measurement of NC, multiple measurements are not needed to be sure about its accuracy.

Compare to BMI, NC has some strength points. NC is measured faster and does not need special tools [9]. Therefore, particularly for epidemiological assessment it seems to be a good predictor. However, due to the high heterogeneity, more studies are needed to clarify its efficacy.

In the present study, we found that the association of NC with obesity, diabetes, hypertension, and MetS were significant in most studies. However, due to limited studies we cannot draw a fix conclusion about these issues. In addition, as there has been no meta-analysis on the SE and the SP of NC as a predictor for MetS, we could not compare our results with previous findings. Based on a systematic review by Arias et al., there was a positive association between $\mathrm{NC}$ and adiposity parameters indirectly measured by reference methods including dual-energy x-ray absorptiometry (DXA) and computed tomography $(\mathrm{CT})$ in adult population. However, they reported no study on children in this regard [50].

The mechanisms that explain the association between neck adipose tissue and cardio-metabolic risk factors are not precisely identified. It is likely that high plasma free fatty acids (FFAs) provide a ground for developing metabolic disorders [36]. Increasing in the levels of FFAs can result in oxidative stress and vascular injury $[15,36]$. The main releasing rate of systemic FFA is dedicated to upper body subcutaneous fat $[5,36]$. Accordingly, NC can be a suitable predictor for CVD risk factors.

The present study has two main limitations: [1] due to cross-sectional design in the most included studies a cause and effect relationship was not clarified. [2] Heterogeneity mostly remained high even after stratification by possible confounders. The main strength of the present 
systematic review was to determine the SE and SP of NC in adult and child populations.

\section{Conclusion}

Although the SE and the SP of NC to predict MetS were acceptable in both child and adult population, the between-study heterogeneity was considerably high. There is a positive association between $\mathrm{NC}$ and glycemic indices, and lipid profile in adult and pre-pubertal populations. However, no correlation was observed between $\mathrm{NC}$ and LDL-C concentrations in children. Due to high heterogeneity, the findings should be declared with caution. Although the association between $\mathrm{NC}$ and other cardio-metabolic risk factors were significant in most studies, due to limited publications in this regard more prospective cohort studies are needed to clarify these associations.

\section{Additional files}

Additional file 1: Figure S1. Forest plot of high neck circumference sensitivity for predicting metabolic syndrome in A) male, B) female, C) children, D) adult population.

Additional file 2: Figure S2. Forest plot of high neck circumference specificity for predicting metabolic syndrome in E) male, F) female, G) children, H) adult population.

Additional file 3: Figure S3. Forest plot of the association of neck circumference and 1) FBS, 2) HOMA, 3) TC, 4) TG, 5) LDL-C in adult population.

Additional file 4: Table S1. Subgroup analysis for the association between neck circumference and cardio-metabolicfactors in adult population.

Additional file 5: Figure S4. Forest plot of the association of neck circumference and 1) FBS, 2) HOMA, 3) TC, 4) TG, 5) LDL-C in child population.

\section{Authors' contributions}

AAJ, NN, SD, PC, MEA, design and data gathering, SSZ, HA, MZ, AMG, MM design and revision, $M Q$ data analysis. All authors read and approved the final manuscript.

\footnotetext{
Author details

${ }^{1}$ Department of Nutrition, Science and Research Branch, Islamic Azad University, Tehran, Iran. ${ }^{2}$ Diabetes Research Center, Endocrinology and Metabolism Clinical Sciences Institute, Tehran University of Medical Sciences, Tehran, Iran. ${ }^{3}$ Development of Research \& Technology Center, Deputy of Research and Technology, Ministry of Health and Medical Education, Tehran, Iran. ${ }^{4}$ Non-communicable Diseases Research Center, Endocrinology and Metabolism Population Sciences Institute, Tehran University of Medical Sciences, Tehran, Iran. ${ }^{5}$ Student Research Committee, Alborz University of Medical Science, Karaj, Iran. ${ }^{6}$ Non-communicable Diseases Research Center, Alborz University of Medical Sciences, Karaj, Iran. ${ }^{7}$ Department of Medical Emergencies, Qom University of Medical Sciences, Qom, Iran. ${ }^{8}$ Department of Nutrition and Dietetics, Faculty of Medicine and Health Sciences, Universiti Putra Malaysia, Serdang, Selangor, Malaysia. ${ }^{9}$ Department of Basic and Clinical Research, Tehran Heart Center, Tehran University of Medical Sciences, Tehran, Iran. ${ }^{10}$ Health Management and Economics Research Center, Iran University of Medical Sciences, Tehran, Iran. ${ }^{11}$ Chronic Diseases Research Center, Endocrinology and Metabolism Population Sciences Institute, Tehran University of Medical Sciences, Tehran, Iran.
}

\section{Acknowledgements}

This study was funded by Alborz University of Medical Sciences. The authors are thankful of Emam Ali clinical research development unit for their assistance.

\section{Competing interests}

The authors declare that they have no competing interests.

Availability of data and materials

Please contact author for data requests.

Consent for publication

Not applicable.

\section{Ethics approval and consent to participate}

The Research and Ethics council of Alborz University of Medical Sciences approved the study (Project number: 394049).

\section{Funding}

Alborz University of Medical Sciences.

\section{Publisher's Note}

Springer Nature remains neutral with regard to jurisdictional claims in published maps and institutional affiliations.

Received: 8 July 2018 Accepted: 14 September 2018

Published online: 29 September 2018

\section{References}

1. Roth GA, Huffman MD, Moran AE, Feigin V, Mensah GA, Naghavi M, et al. Global and regional patterns in cardiovascular mortality from 1990 to 2013. Circulation. 2015;132(17):1667-78.

2. Handbook of Obesity (2nd Edition)-George A. Bray Claude Bouchard0824747739-Informa Healthcare.pdf >

3. Despres JP, Lemieux I, Bergeron J, Pibarot P, Mathieu P, Larose E, et al. Abdominal obesity and the metabolic syndrome: contribution to global cardiometabolic risk. Arterioscler Thromb Vasc Biol. 2008;28(6):1039-49.

4. Ben-Noun L, Sohar E, Laor A. Neck circumference as a simple screening measure for identifying overweight and obese patients. Obes Res. 2001;9(8):470-7.

5. Hingorjo MR, Qureshi MA, Mehdi A. Neck circumference as a useful marker of obesity: a comparison with body mass index and waist circumference. J Pak Med Assoc. 2012;62(1):36-40.

6. Ben-Noun LL, Laor A. Relationship between changes in neck circumference and changes in blood pressure. Am J Hypertens. 2004;17(5 Pt 1):409-14.

7. Ozkaya I, Tunckale A. Neck circumference positively related with central obesity and overweight in Turkish university students: a preliminary study. Cent Eur J Public Health. 2016;24(2):91-4.

8. Ma C, Wang R, Liu Y, Lu Q, Liu X, Yin F. Diagnostic performance of neck circumference to identify overweight and obesity as defined by body mass index in children and adolescents: systematic review and meta-analysis. Ann Hum Biol. 2017;44(3):223-9.

9. Yan $Q$, Sun D, Li X, Zheng Q, Li L, Gu C, et al. Neck circumference is a valuable tool for identifying metabolic syndrome and obesity in Chinese elder subjects: a community-based study. Diabetes Metab Res Rev. 2014;30(1):69-76.

10. Yang GR, Yuan SY, Fu HJ, Wan G, Zhu LX, Bu XL, et al. Neck circumference positively related with central obesity, overweight, and metabolic syndrome in Chinese subjects with type 2 diabetes: Beijing Community Diabetes Study 4. Diabetes Care. 2010;33(11):2465-7.

11. Luo Y, Ma X, Shen Y, Xu Y, Xiong Q, Zhang X, et al. Neck circumference as an effective measure for identifying cardio-metabolic syndrome: a comparison with waist circumference. Endocrine. 2017;55(3):822-30.

12. Gonçalves VSS, Faria ERD, Franceschini SDCC, Priore SE. Neck circumference as predictor of excess body fat and cardiovascular risk factors in adolescents. Revista de Nutrição. 2014;27(2):161-71.

13. Selvan C, Dutta D, Thukral A, Nargis T, Kumar M, Mukhopadhyay S, et al. Neck height ratio is an important predictor of metabolic syndrome among Asian Indians. Indian J Endocrinol Metab. 2016;20(6):831. 
14. Khalangot M, Gurianov V, Okhrimenko N, Luzanchuk I, Kravchenko V. Neck circumference as a risk factor of screen-detected diabetes mellitus: community-based study. Diabetol Metab Syndr. 2016;8(1):12.

15. Silva CdCd, Zambon MP, Vasques ACJ, Rodrigues AMdB, Camilo DF, Antonio MÂR, et al. Neck circumference as a new anthropometric indicator for prediction of insulin resistance and components of metabolic syndrome in adolescents: Brazilian Metabolic Syndrome Study. Rev Paul Pediatr. 2014;32(2):221-9.

16. Gomez-Arbelaez D, Camacho PA, Cohen DD, Saavedra-Cortes S, LopezLopez C, Lopez-Jaramillo P. Neck circumference as a predictor of metabolic syndrome, insulin resistance and low-grade systemic inflammation in children: the ACFIES study. BMC Pediatr. 2016;16(1):31.

17. Pereira DCR, Araúijo MFMd, Freitas RWJFd, Teixeira CRdS, Zanetti ML, Damasceno MMC. Neck circumference as a potential marker of metabolic syndrome among college students. Rev Lat Am Enfermagem. 2014;22(6):973-9.

18. J-y Zhou, Ge H, M-f Zhu, L-j Wang, Chen L, Y-zTan, et al. Neck circumference as an independent predictive contributor to cardio-metabolic syndrome. Cardiovasc Diabetol. 2013;12(1):76.

19. Cho NH, Oh TJ, Kim KM, Choi SH, Lee JH, Park KS, et al. Neck circumference and incidence of diabetes mellitus over 10 years in the Korean genome and epidemiology study (KoGES). Sci Rep. 2015;5:18565.

20. de Lucena Ferretti $R$, de Pádua Cintra I, Passos MAZ, de Moraes Ferrari GL, Fisberg M. Elevated neck circumference and associated factors in adolescents. BMC Public Health. 2015;15(1):208.

21. Kelishadi R, Djalalinia S, Motlagh ME, Rahimi A, Bahreynian M, Arefirad $T$, et al. Association of neck circumference with general and abdominal obesity in children and adolescents: the weight disorders survey of the CASPIAN-IV study. BMJ Open. 2016;6(9):e011794.

22. Kuciene R, Dulskiene V, Medzioniene J. Association of neck circumference and high blood pressure in children and adolescents: a case-control study. BMC Pediatr. 2015;15(1):127.

23. Formisano A, Bammann K, Fraterman A, Hadjigeorgiou C, Herrmann D, lacoviello L, et al. Efficacy of neck circumference to identify metabolic syndrome in 3-10 year-old European children: results from IDEFICS study. Nutr Metab Cardiovasc Dis. 2016;26(6):510-6.

24. Kurtoglu S, Hatipoglu N, Mazicioglu MM, Kondolot M. Neck circumference as a novel parameter to determine metabolic risk factors in obese children. Eur J Clin Invest. 2012;42(6):623-30.

25. Hatipoglu N, Mazicioglu MM, Kurtoglu S, Kendirci M. Neck circumference: an additional tool of screening overweight and obesity in childhood. Eur J Pediatr. 2010;169(6):733-9.

26. Kumar NV, Ismail MH, Mahesha P, Girish M, Tripathy M. Neck circumference and cardio-metabolic syndrome. J Clin Diagn Res. 2014;8(7):MC23.

27. Pillai BP, Kumar H, Jayakumar RV, Alur VC, Sheejamol V. The prevalence of metabolic syndrome in polycystic ovary syndrome in a South Indian population and the use of neck circumference in defining metabolic syndrome. Int J Diabetes Dev Ctries. 2015;35(4):469-75.

28. Androutsos O, Grammatikaki E, Moschonis G, Roma-Giannikou E, Chrousos G, Manios Y, et al. Neck circumference: a useful screening tool of cardiovascular risk in children. Pediatr Obes. 2012;7(3):187-95.

29. Hassan NE, Atef A, El-Masry SA, Ibrahim A, Al-Tohamy M, Rasheed EA, et al. Is neck circumference an indicator for metabolic complication of childhood obesity? Open Access Maced J Med Sci. 2015;3(1):26.

30. Fitch KV, Stanley TL, Looby SE, Rope AM, Grinspoon SK. Relationship between neck circumference and cardiometabolic parameters in HIVinfected and non-HIV-infected adults. Diabetes Care. 2011;34(4):1026-31.

31. Savva S, Tornaritis M, Savva M, Kourides Y, Panagi A, Silikiotou N, et al. Waist circumference and waist-to-height ratio are better predictors of cardiovascular disease risk factors in children than body mass index. Int J Obes. 2000;24(11):1453.

32. De Koning L, Merchant AT, Pogue J, Anand SS. Waist circumference and waist-to-hip ratio as predictors of cardiovascular events: meta-regression analysis of prospective studies. Eur Heart J. 2007;28(7):850-6.

33. Dixon JB, O'brien PE. Neck circumference a good predictor of raised insulin and free androgen index in obese premenopausal women: changes with weight loss. Clin Endocrinol. 2002;57(6):769-78.

34. Hoebel S, Swanepoel M, Malan L. Examining waist and neck circumferences as screening tools for metabolic syndrome in a sub-Saharan Caucasian cohort at three year follow-up: the SABPA prospective cohort. J Endocrinol Metab Diabetes S Afr. 2014;19(3):106-12.
35. Preis SR, Massaro JM, Hoffmann U, D’Agostino RB Sr, Levy D, Robins SJ, et al. Neck circumference as a novel measure of cardiometabolic risk: the Framingham Heart study. J Clin Endocrinol Metab. 2010;95(8):3701-10.

36. Liang J, Teng F, Liu X, Zou C, Wang Y, Dou L, et al. Synergistic effects of neck circumference and metabolic risk factors on insulin resistance: the cardiometabolic risk in Chinese (CRC) study. Diabetol Metab Syndr. 2014;6(1):116.

37. Torriani M, Gill CM, Daley S, Oliveira AL, Azevedo DC, Bredella MA. Compartmental neck fat accumulation and its relation to cardiovascular risk and metabolic syndrome. Am J Clin Nutr. 2014;100(5):1244-51.

38. Cizza G, de Jonge L, Piaggi P, Mattingly M, Zhao X, Lucassen E, et al. Neck circumference is a predictor of metabolic syndrome and obstructive sleep apnea in short-sleeping obese men and women. Metab Syndr Relat Disord. 2014;12(4):231-41.

39. Zepeda A, Curcio C, Nafiu O, Prasad Y. Association of neck circumference and obesity status with elevated blood pressure in children. J Hum Hypertens. 2013;28(4):263.

40. Katz SL, Vaccani J-P, Clarke J, Hoey L, Colley RC, Barrowman NJ. Creation of a reference dataset of neck sizes in children: standardizing a potential new tool for prediction of obesity-associated diseases? BMC Pediatr. 2014;14(1):159.

41. Lou D-H, Yin F-Z, Wang R, Ma C-M, Liu X-L, Lu Q. Neck circumference is an accurate and simple index for evaluating overweight and obesity in Han children. Ann Hum Biol. 2012;39(2):161-5.

42. Atwa $\mathrm{H}$, Fiala L, Handoka NM. Neck circumference as an additional tool for detecting children with high body mass index. J Am Sci. 2012;8(10):442-6.

43. Guo X, Li Y, Sun G, Yang Y, Zheng L, Xingang Z, et al. Prehypertension in children and adolescents: association with body weight and neck circumference. Intern Med. 2012;51(1):23-7.

44. Vallianou NG, Evangelopoulos AA, Bountziouka V, Vogiatzakis ED, Bonou MS, Barbetseas J, et al. Neck circumference is correlated with triglycerides and inversely related with $\mathrm{HDL}$ cholesterol beyond BMI and waist circumference. Diabetes Metab Res Rev. 2013;29(1):90-7.

45. Zen V, Fuchs FD, Wainstein MV, Gonçalves SC, Biavatti K, Riedner CE, et al. Neck circumference and central obesity are independent predictors of coronary artery disease in patients undergoing coronary angiography. Am J Cardiovasc Dis. 2012;2(4):323.

46. Rao KSP, Dinesh PV. Association of blood pressure in adults with selected anthropometric parameters and CRP: a hospital based cross sectional study. J Evol Med Dent Sci JEMDS. 2016:5(51):3383-8.

47. Li H-X, Zhang F, Zhao D, Xin Z, Guo S-Q, Wang S-M, et al. Neck circumference as a measure of neck fat and abdominal visceral fat in Chinese adults. BMC Public Health. 2014;14(1):311.

48. Saka M, Türker P, Ercan A, Kızıltan G, Bas M. Is neck circumference measurement an indicator for abdominal obesity? A pilot study on Turkish Adults. Afr Health Sci. 2014;14(3):570-5.

49. Joshipura K, Muñoz-Torres F, Vergara J, Palacios C, Pérez CM. Neck circumference may be a better alternative to standard anthropometric measures. J Diabetes Res. 2016. https://doi.org/10.1155/2016/6058916.

50. Arias MT, Martinez-Tellez B, Soto J, Sanchez-Delgado G. Validity of neck circumference as a marker of adiposity in children and adolescents, and in adults: a systematic review. Nutr Hosp. 2018;35(3):707-21.

Ready to submit your research? Choose BMC and benefit from

- fast, convenient online submission

- thorough peer review by experienced researchers in your field

- rapid publication on acceptance

- support for research data, including large and complex data types

- gold Open Access which fosters wider collaboration and increased citations

- maximum visibility for your research: over 100M website views per year

At BMC, research is always in progress.

Learn more biomedcentral.com/submissions 